\title{
Review Article \\ Pivotal Cytoprotective Mediators and Promising Therapeutic Strategies for Endothelial Progenitor Cell-Based Cardiovascular Regeneration
}

\author{
Hyunyun Kim, ${ }^{1}$ Sujin Kim, ${ }^{1}$ Sang Hong Baek, ${ }^{2}$ and Sang-Mo Kwon ${ }^{1}$ \\ ${ }^{1}$ Laboratory for Vascular Medicine and Stem Cell Biology, Convergence Stem Cell Research Center, Medical Research Institute, \\ Pusan National University School of Medicine, Yangsan, Republic of Korea \\ ${ }^{2}$ Laboratory of Cardiovascular Regeneration, Division of Cardiovascular Medicine, Seoul St. Mary's Hospital, \\ The Catholic University of Korea School of Medicine, Seoul, Republic of Korea
}

Correspondence should be addressed to Sang Hong Baek; whitesh@catholic.ac.kr and Sang-Mo Kwon; smkwon323@hotmail.com Received 15 August 2016; Revised 11 October 2016; Accepted 27 October 2016

Academic Editor: Michael Lichtenauer

Copyright (C) 2016 Hyunyun Kim et al. This is an open access article distributed under the Creative Commons Attribution License, which permits unrestricted use, distribution, and reproduction in any medium, provided the original work is properly cited.

Cardiovascular diseases (CVDs), including atherosclerosis, stroke, and myocardial infarction, is a major cause of death worldwide. In aspects of cell therapy against CVD, it is generally accepted that endothelial progenitor cells (EPCs) are potent neovascular modulators in ischemic tissues. In response to ischemic injury signals, EPCs located in a bone marrow niche migrate to injury sites and form new vessels by secreting various vasculogenic factors including VEGF, SDF-1, and FGF, as well as by directly differentiating into endothelial cells. Nonetheless, in ischemic tissues, most of engrafted EPCs do not survive under harsh ischemic conditions and nutrient depletion. Therefore, an understanding of diverse EPC-related cytoprotective mediators underlying EPC homeostasis in ischemic tissues may help to overcome current obstacles for EPC-mediated cell therapy for CVDs. Additionally, to enhance EPC's functional capacity at ischemic sites, multiple strategies for cell survival should be considered, that is, preconditioning of EPCs with function-targeting drugs including natural compounds and hormones, virus mediated genetic modification, combined therapy with other stem/progenitor cells, and conglomeration with biomaterials. In this review, we discuss multiple cytoprotective mediators of EPC-based cardiovascular repair and propose promising therapeutic strategies for the treatment of CVDs.

\section{Introduction}

Excessive nutrient intake from food affects public health $[1,2]$. In particular, immoderate intake of salt [3], fat [4], and sugars [5] is closely related to cardiovascular diseases (CVDs). These CVD-inducing factors are present in blood and circulate with blood. High concentrations of sodium, lipids, and glucose require additional blood to sustain blood homeostasis [6]. To pump blood as a routine task, the heart requires enhanced contractile force. This process strains the heart and causes cardiac diseases including angina [7], cardiac infarction [8], and arrhythmia [9] as well as high blood pressure [10] and onset of damage to vessels. In addition, excessive nutrient causes pathogenesis of CVDs. For instance, over-intake lipids are deposited in the arterial blood vessel and narrow the vessel diameter. Endothelial inflammatory mechanism is activated, sequentially triggering migration of inflammatory cells toward the lipid-accumulated site of blood vessel. These cells ingest lipid and transform themselves into foam cells, a pathologic elements of atheroma [11], which are conjugated with smooth muscle cells (SMCs) and generate fibrous extracellular matrix in the lesions. Caplike structure of mixture is weakened by the proteolytic enzyme from inflammatory cells and easy to rupture [12]. Although blood vessels maintain their physical condition, the loss and insufficient durability of blood vessels cause CVDs, including atherosclerosis [13], stroke, and ischemia [14]. To identify the best therapeutic approach to CVDs, traditional studies have been focused on pharmacotherapy of CVDs, with an obvious limitation incomplete functional recovery from a CVD as well as side effects including diarrhea, rash, or itching. Recently, advances in stem cell biology, directly 
targeting potent cytoprotective mediators in injured tissues via an in situ transplant of stem and progenitor cells, have highlighted the strong potential of stem cell-based therapy against ischemic CVDs.

In 1997, Asahara et al. discovered the presence of endothelial progenitor cells (EPCs) in human blood. EPCs reside in a bone marrow (BM) niche and interact with neighboring cells or niche-forming cells. In response to ischemic signals, these progenitors are dramatically mobilized to blood vessels and are incorporated into injury sites [15]. EPCs engrafted in ischemic tissue then differentiate into their designated cell types: endothelial cells (ECs) or SMCs. Impaired vascular tissues are replaced with newly arriving and differentiated cells [16]. During the process of recovery from injury, pivotal cytoprotective mediators including well-known signaling pathways such as HIF-1 $\alpha$-dependent signals, Akt-dependent prosurvival signals, eNOS signaling, stromal-cell-derived factor $1 \alpha$-dependent tissue incorporation signals, and several growth factors including vascular endothelial growth factor (VEGF) and fibroblast growth factor (FGF) have recently been reported in studies on EPC biology $[17,18]$.

In studies aimed at better clinical use of EPCs against ischemic CVDs, accumulating data have recently shown stronger therapeutic strategies involving targeting of these cytoprotective modulators, which may be linked to cell-cell interactions, cell-extracellular matrix (ECM) interactions, and upregulated proangiogenic cytokines and intracellular survival signals in ischemic tissues [19]. One of the most straightforward ideas for enhancing EPC function is the drug-based preconditioning strategy before the cell transplant into an ischemic site [20]. Compared to commercial drugs, natural compounds have some advantages, because they can be easily isolated from animals or plants and have less harmful side effects than artificial drugs. The other method is to enhance cell survival via genetic modification of the transplanted cells using an improved vector delivery system. Recently, retrovirus- [21], lentivirus- [22], and adenoassociated virus- (AAV-) mediated gene delivery systems [23] were shown to have distinct mechanisms, advantages, and flaws. A combinatorial cell therapy using two types of cells might be another powerful recovery enhancing strategy [24]. For example, a combination of EPCs and supporting cells may contribute to regeneration of not only vascular tissue but also other tissues including neurons, muscle, bone, and pancreas because restored blood vessels are capable of supplying sufficient blood with nutrients to a damaged tissue with effectively recruited hybridized partner cells including mesenchymal stem cells (MSCs) and $\beta$-cell islets [25]. Another emerging topic in stem cell therapy is artificial nichemediated strategies involving transplanted cells including three-dimensional (3D) spheroid cells, artificial tissues constructed by 3D printing technologies, and biomaterial-based scaffold strategies, which may consist of living-organismfriendly niche components and protect EPCs from a harsh ischemic environment and nutrient depletion $[26,27]$.

In this review, we describe recent progress of EPC biology, discuss multiple topics on cytoprotective mediators of EPCbased cardiovascular repair, and offer promising therapeutic strategies for the treatment of CVDs.

\section{EPC-Based Cardiovascular Repair}

2.1. The Basics of EPC. In 1997, Asahara et al. first isolated EPCs from adult peripheral blood [28]. In addition to peripheral blood, EPCs can be isolated from various sources including BM [29], cord blood (CB) [30], fetal liver [31], and skeletal muscle [32]. These rare populations of cells can be mobilized into the circulation by diverse stimuli [33]. In response to growth factors and cytokines released during atherosclerosis [34], myocardial infarction [35], wound healing [36], limb ischemia [37], or tumor angiogenesis [38], EPCs are capable of homing to sites of a damaged endothelium or extravascular tissue and producing abundant angiogenic cytokines for promotion of in situ cell proliferation and vascular cell lineage differentiation; EPCs also directly differentiate into mature vascular endothelial cells. They are isolated as $\mathrm{CD} 34^{+}$cells from human peripheral blood and are cultured in a plate with a fibronectin-coated surface, forming endothelial-like cells [28]. After a few hours, early EPCs express typical EPC markers including CD34 (mucosialin) [39] and vascular endothelial growth factor receptor-2 (VEGFR-2) [40, 41]. Particularly, hematopoietic stem and progenitor cells coexpress a marker of immature human stem cells, CD133, also called the early hematopoietic-stem cell marker. In contrast to the progenitor marker CD34, mature endothelial cells or endothelial colony forming cells (ECFCs) do not express CD133 [42]. For this reason, a combination of these three markers of $\mathrm{CD} 34^{+}, \mathrm{CD} 133^{+}$, and VEGFR-2 ${ }^{+}$was recently reported as a promising EPC marker by some research groups $[43,44]$. Nonetheless, identification of the unique surface marker of EPCs is still a controversial topic, which should be addressed in the near future $[43,45,46]$.

The heart and circulatory system need a sufficient EPC number to keep the body healthy. Schmidt-Lucke et al. have studied the correlation between the number of circulating EPCs and future cardiovascular events in patients [47]. They tried to trace circulating EPCs with defined surface markers CD34 and KDR by flow cytometry; the 120 individuals were followed up for 10 months. Decreased numbers of EPCs were found to be associated with a higher incidence of CVDs. Jie et al. have reported a tight link between hemodialysis and circulating EPC numbers in children with chronic kidney disease [48] after studying $\mathrm{CD} 34^{+} \mathrm{KDR}^{+}$EPC numbers by flow cytometry. Children with chronic kidney disease [49] on hemodialysis showed $47 \%$ lower EPC levels as compared with the control. Compared to the hemodialysis chronic kidney disease group, however, children with predialysis chronic kidney disease showed no significant change. This result is in line with studies on adult patients [50]. Therefore, the uremic environment in patients with chronic kidney disease does not reduce EPC levels, but a reduced number of circulating EPCs can primarily contribute to CVD or coronary artery disease (CAD) [51]. Similarly, Eizawa et al. showed that patients with CAD have reduced number of circulating EPCs [52]. Using flow cytometry, those researchers demonstrated that circulating $\mathrm{CD} 34^{+}$cells are significantly downregulated in patients with $\mathrm{CAD}$ and the cell number is approximately $30 \%$ lower than that among age-matched control subjects. 
2.2. Two Types of EPCs: Early EPCs and Late EPCs. Diverse research groups have isolated ex vivo-cultured EPCs from various tissues by different culture methods and characterized EPCs by means of distinct cell surface markers and endothelial-lineage-related functional assays. According to recent progress in EPC biology, EPCs are subdivided into two types: early EPCs and late EPCs. Early EPCs have spindleshaped morphology with a short lifespan. These early EPCs strongly express CD45 [53], vascular endothelial growth factor receptor 1 (Flt1 or VEGFR1) [54], endothelial nitric oxide synthase (eNOS) [55], Von Willebrand factor (vWF) [56], and CD31 [57]. After 3 weeks, the expression of KDR and VE-cadherin disappears and cells die. On the other hand, late EPCs were obtained by prolonged incubation of peripheral mononuclear cells (MNCs) in the presence of VEGF [58]. These cells' morphology changes to cobblestone monolayerlike morphology of human umbilical vein endothelial cells (HUVECs) [59], but their proliferation potential is higher than that of HUVECs. Gene expression profiles of early EPCs and late EPCs also show difference. The expression levels of surface marker genes including CD14, Flt-1, and KDR [60] in early EPCs are inconsistent among reports by many groups [61] because early EPCs are a heterogeneous subpopulation. Nevertheless, gene expression profiles of late EPCs are quite similar to the profile of HUVECs. Compared to early EPCs, the KDR expression level is higher in late EPCs. Therefore, late EPCs show better capacity for formation of tubule-like structures and a stronger long-term survival potential in comparison with early EPCs. Early EPCs, however, can contribute to neovascularization by secreting greater amounts of angiogenic factors such as VEGF and interleukin 8 (IL-8) [62] than late EPCs do.

\section{Understanding EPC-Mediated Vascular Repair}

3.1. BM Niche as a Hometown of EPCs. Because EPCs and hematopoietic stem cells (HSCs) originate from derived from a hemangioblasts $[63,64]$, EPCs share diverse stem/progenitor specific markers with HSCs such as CD34, CD133, c-kit [65], and Sca-1 [66, 67]. Just as HSCs, EPCs mainly develop in BM [68] and are located in the osteoblastic niche, endosteal niche [69], and vascular niche [70]. Stem cells in the osteoblastic niche are recruited to the vascular niche via cytokines such as SDF-1. Thereafter, the migrating cells differentiate into committed progenitors as needed and set the stage for full reconstitution of BM [71]. Signaling pathways such as Ang-1/Tie2 [72], stem cell factor (SCF)/c-Kit [73], SDF-1/CXCR4 [74], and Jagged/Notch [75] of HSCs in $\mathrm{BM}$ niches play a critical role in a niche [76], whereas the origin of EPCs and their lineage determination in BM are not fully understood.

The undifferentiated progenitor cells including HSCs and EPCs also express c-Kit receptor, an immaturity marker. Heissig et al. recently reported the niche-modulation signals of stem/progenitor cells [77]. After myelosuppression by means of 5-fluorouracil, the expression level of matrix metalloproteinase-9 (MMP-9) is increased, and thereby MMP-9 promotes release of sKitL from the membrane form (mKitL).
Furthermore, myelosuppression significantly induces stem cell mobilizing cytokines including SDF-1, G-CSF, and VEGF and stimulates a release of pro-MMP-9 and migration of human $\mathrm{CD} 34^{+}$stem/progenitor cells. Indeed, increased SDF1 and VEGF levels in the plasma of wild-type (WT) mice enhance mobilization of circulating EPC, suggesting that recruitment and mobilization of BM-derived circulating EPCs require activation of MMP-9.

Another pivotal cytoprotective modulator in BM-EPC biology contributing to functional kinetics of the BM microenvironment is the Notch signaling pathway [78]. Although many research groups have studied Notch signaling pathways with respect to stem cell biology, relations between BM- and EPC-mediated vasculogenesis have not been fully elucidated [79]. Kwon et al. studied niche modulation of Jagged-1mediated Notch signaling in a BM microenvironment [80]. Notch ligands (Jag-1 and Dll-1) are expressed by these nichesupporting cells [81]. Compared to WT and Dll-1 ${ }^{-/-}$mouse cells, Jag- $1^{-1-}$ cells form fewer EPC colonies. This result is similar to the finding that $\gamma$-secretase II, a blocker of cleavage of the intracellular domain in Notch receptor, mediates inhibition of Notch signaling in BM-KSL cells $\left(\mathrm{Kit}^{+} \mathrm{Sca}-1^{+} \mathrm{Lin}^{-}\right)$. To test the contribution of Notch signals to recovery from ischemia, they generated a hindlimb ischemia model and transplanted EPCs from BM of each $\mathrm{KO}$ mouse. Unlike BM EPCs from WT and Dll-1-1- mice, BM EPCs derived from Jag- $1^{-1-}$ mice fail to augment blood perfusion, suggesting that EPCs are affected by the niche microenvironment of BM, and EPCs preconditioned by a specific Jag-1-dependent signaling pathway may be useful for therapeutic neovascularization [81] (Figure 1).

The Lnk adaptor protein with a Src homology 2 domain has been studied in B cells and HSCs $[82,83]$. This gene is highly expressed in immature cells and act as a negative regulator of the SCF/c-Kit signaling. On the basis of the findings of this study, Kwon et al. also investigated the cytoprotective role of Lnk in EPC biology [84]. The lnk expression levels were found to be higher in BM hematopoietic and endothelial progenitors than among other differentiated BM cells. Specific deletion of the $\ln k$ gene results in an increase in immature subpopulation of $\mathrm{KSL}\left(\mathrm{Kit}^{+} / \mathrm{Sca}^{+} / \mathrm{Lin}^{-}\right)$cells and significantly upregulates endothelial markers including Flk-1, VEcadherin, CD31, and CXCR4 in lnk ${ }^{-/-}$mice but not WT mice. Blood flow in the hindlimb ischemic region containing transplanted EPCs is significantly enhanced in $1 \mathrm{nk}^{-/-}$mice. Moreover, EPC survival-related genes, Akt and eNOS, are also upregulated in $\mathrm{lnk}^{-/-}$mice, providing strong evidence that the Lnk adaptor protein is a downstream target of the SCF-cKit axis and a definitive modulator of the BM-EPC niche.

3.2. Mobilization of EPCs into Injured Tissues. Progenitor cells in a niche are dramatically mobilized to an impairedtissue region in response to various cytokines. In 1999, Takahashi et al. first studied ischemia- and cytokine-induced EPC mobilization in relation to neovascularization [85]. They generated a mouse model and rabbit model of hindlimb ischemia to test the effect of granulocyte macrophage-colony stimulating factor (GM-CSF) [86] on neovascularization of 


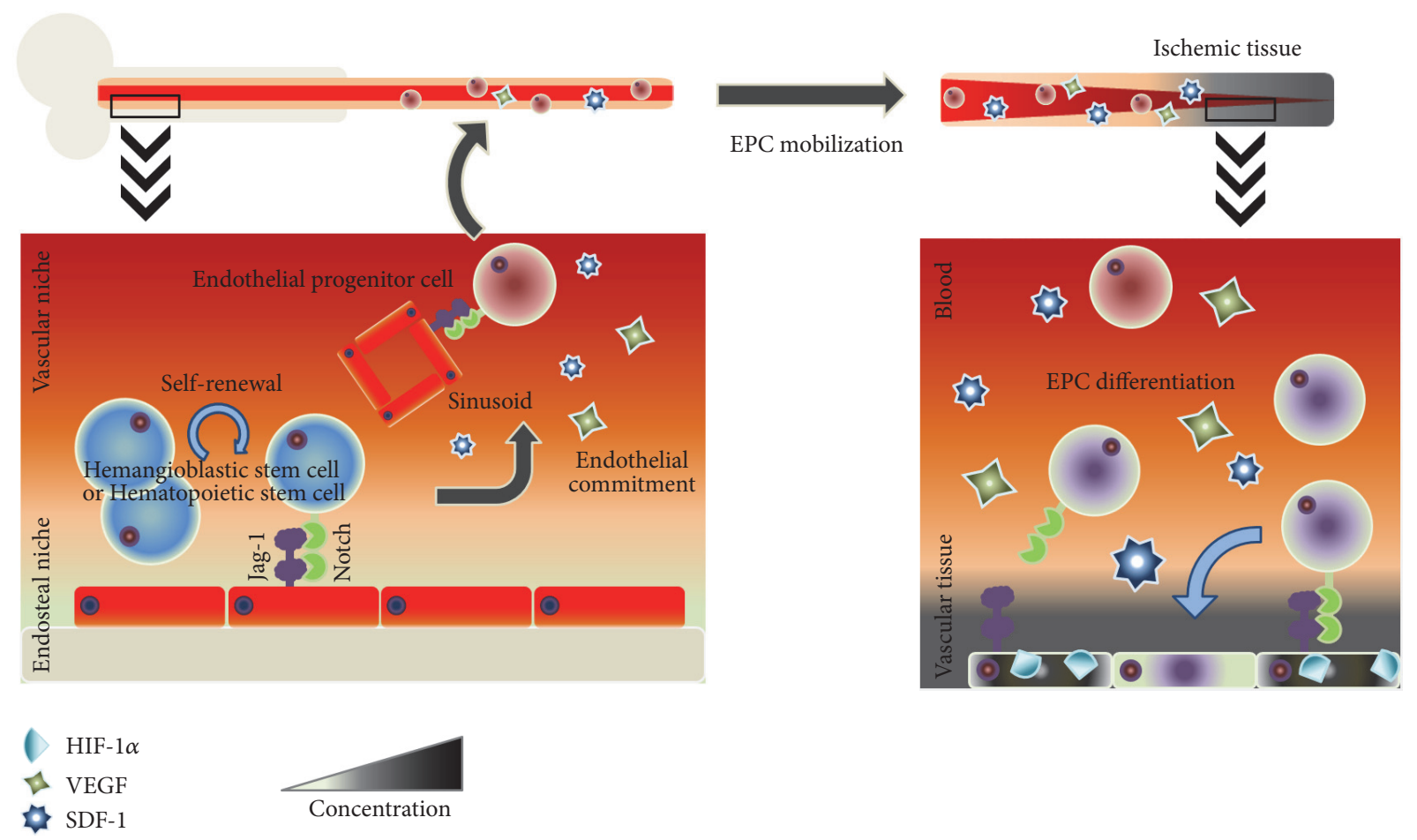

FIGURE 1: EPC homing from a BM niche to the circulation. HSCs and EPCs interact with stromal niche cells via Notch signals. HIF-1 $\alpha$, stabilized from ischemic signals, promotes EPC homing-related cytokines, including VEGF and SDF-1.

ischemic tissue. In this model, GM-CSF promotes neovascularization in ischemic tissue, and fluorescent photomicrographs show increased neovascularization in avascular area. Besides GM-CSF, many other cytokines with a specific signaling pathway have been implicated in neovascularization. Accumulating evidence has revealed the importance of various factors including SDF-1, VEGF, placenta-derived growth factor (PIGF), platelet-derived growth factor (PDGF), GM-CSF, and IL-6 [87] in the process of EPC mobilization.

One of the well-known angiogenic cytokines is VEGF [88]. HIF is upregulated under hypoxic conditions [89]. In damaged endothelial cells (ECs) or cancer cells, HIF binds to the promoter region of VEGF [90]. EPCs express VEGFR-1 and VEGFR-2 (KDR or flt-1) on the surface of their plasma membrane. Overproduction of VEGF at ischemic sites and in a $\mathrm{BM}$ niche leads to EPC mobilization. The VEGFRVEGF complex activates the phosphatidylinositol 3-kinase(PI3K-) AKT pathway [91] and thereby is linked to activation of MMP-9, cathepsin, and plasminogen activators, which consequently digest the ECM to promote EPC migration, resulting in enhanced neovascularization [92].

Similarly, stromal-cell-derived factor 1 (SDF-1), also known as CXC motif chemokine 12 , is upregulated in ischemic diseases such as myocardial infarction and stroke $[93,94]$. Similar to VEGF, stromal SDF-1 is directly targeted and strongly induced by HIF- $1 \alpha$ because the promoter region of SDF-1 contains a HIF- $1 \alpha$ binding site. Chemokine receptor CXC motif chemokine receptor 4 (CXCR4) is highly expressed in EPCs [95]. Accumulating evidence reveals that the SDF-1-CXCR4 complex plays a crucial role in EPCs' homing to an ischemic site $[96,97]$. SDF- $1 \alpha$ promotes migration of ECs or EPCs by activating JNK3. eNOS, activated via SDF-1 $\alpha / A k t$, produces nitric oxide (NO) and nitrosylates MAPK phosphatase 7 (MKP7), suggesting that eNOS and JNK3 contribute to SDF- $1 \alpha$-dependent migration of ECs or EPCs [98]. On the other hand, a CXCR4 knock-out is lethal and exhibit impaired kidney vasculogenesis [99], indicating that SDF-1-CXCR4 axis may play a critical role in EPC mobilization for neovascularization.

3.3. Incorporation of EPCs into Damaged Tissues. Incorporation of EPCs into ischemic tissue requires a multiple process [100]. Damaged vascular tissue secretes chemotaxis. According to chemotaxis gradient, EPCs are homing to ischemic region. After that, invasion process is activated. EPCs migrate into vascular tissue, release growth factor, and differentiate into blood vessel cell. To maintain strong structure of blood vessel, adhesion molecules are expressed and connect to neighbor cells.

Homed EPCs are preparing invasion process. Homed EPC and EC, preexisting in vascular tissue, express their surface adhesion molecule. Adhesion molecules expressed on ECs including E-selectin, L-selectin, and P-selectin perform a crucial function in their attachment to ischemic tissues. Both P-selectin glycoprotein ligand-1 (PSGL-1) and sialylated carbohydrate molecules bind to selectin family proteins [101]. $\mathrm{Oh}$ et al. demonstrated a pivotal role of E-selectin in EPCmediated neovascularization [102]. An in vitro adhesion assay revealed that blocking of E-selectin using specific antibodies significantly decreases the adhesion ability of EPCs in a 
gelatin-coated plate. In an ischemic-hindlimb model based on genetically E-selectin-deficient mice, those researchers showed that attachment of homed EPCs to an ischemic limb is severely impaired in E-selectin knock-out mice, whereas injected E-selectin significantly rescued the new vessel formation ability in an ischemic hindlimb of E-selectin knock-out mice. In addition to previous described adhesion molecules, vascular cell adhesion protein-1 (VCAM1), intercellular adhesion molecule-1 (ICAM-1), and very late antigen-4 (VLA-4 or integrin $\alpha 4 \beta 1$ ) integrin/lymphocyte function-associated antigen 1 (LFA-1) play important role in this process. VCAM-1 and/or ICAM-1 tightly bind to integrin $\alpha 4 \beta 1$ and LFA-1. This complex facilitates penetration of EPCs into EC-EC connections and transendothelial migration [103, 104]. Upregulated chemotactic signaling molecules stimulate EPCs to secrete MMP-9 or cathepsin L. EPC-EC binding molecules, including integrins, ECM molecules, and ligandreceptor complexes such as SDF-1/CXCR4, are cleaved by MMP-9/cathepsin L (CathL) [105]. Urbich et al. examined CathL expression levels in HUVECs, EPCs, and CD14 ${ }^{+}$ cells and showed significantly increased levels of CathL in EPCs [106]. Furthermore, genetically CathL-deficient mice $\left(\right.$ Cath $\left.^{-/-}\right)$show impaired neovascularization, suggesting that the MMP-9-cathepsin L axis may be strongly involved in recovery of damaged tissues by promoting the EC-ECM interaction.

As a result, newly incorporated EPCs are getting mature and differentiate into EC. Integrins, such as $\beta 1$ and $\alpha_{\gamma} \beta 5$, contribute to strong connection between new and old cell $[107,108]$.

\section{Cytoprotective Mediators in EPC Biology for Better Cellular Longevity}

Most of transplanted EPCs seldom survive under the harsh conditions of ischemia, inflammation, oxidative stress, and mechanical stress [109]. To prevent cell loss and improve the survival rate of EPCs at ischemic sites, tremendous research efforts have eventually uncovered several pivotal cytoprotective mediators relevant to EPC survival in an ischemic environment.

Akt, a serine-threonine protein kinase, is a major regulator of cell growth, differentiation, and cell survival and death. In response to VEGF, SDF-1, angiotensin 1, or reactive oxygen species (ROS), the PH domain of Akt binds to PI3K. Thr308 and Ser473 are sequentially phosphorylated by 3phosphoinositide-dependent protein kinase 1 (PDK1) and PDK2 and consequently activate the downstream effectors [110]. Hur et al. demonstrated a cytoprotective effect of Akt during EPC-mediated neovascularization [111]. They isolated EPCs from 1, $1^{\prime}$-dioctadecyl-3,3,3',3'-tetramethylindocarbocyanine-labeled mice. When systemically administered, these EPCs can show each stage of homing to an ischemic limb. In ischemic muscle, ischemia induces VEGF expression, SDF-1 activates Akt signaling in ECs and consequently upregulates Akt-enhanced ICAM-1 expression on ECs. Due to the increased expression level of ICAM-1, EPCs can easily intermingle with ECs, suggesting that activated Akt may be sufficient for induction of EPC homing without
VEGF or SDF-1. They further demonstrated that Akt genetransferred ischemic tissue shows enhanced homing of EPCs, vessel formation, blood flow recovery, and ischemic tissue indication, providing that specific regulation of Akt in EPC biology may be a novel therapeutic target in ischemic organs.

Reactive oxygen species- (ROS-) related signals are key cytoprotective mediators that improve cell survival of transplanted EPCs in a harsh ischemic microenvironment. Smooth muscle cells (SMCs) and ECs from injured tissue robustly produce ROS. These highly reactive chemicals then approach the artery wall and react with low-density lipoprotein (LDL). Uncontrolled ROS levels in a blood vessel cause atherosclerosis [112]. Zhang et al. demonstrated the cytoprotective properties of an ROS scavenger in EPC biology using atherosclerosis models [113]. Treatment with oxidized LDL (Ox-LDL) reduces the numbers of circulating MNCs and EPCs, and this effect is attenuated by probucol, an ROS scavenger. Electron paramagnetic resonance data indicate that ROS generated by ox-LDL are eliminated by probucol. In murine BM analysis, probucol-treated hyperlipidemic mice show an elevated number of EPCs. Probucol downregulates ox-LDL and C-reactive protein (CRP) and upregulates superoxide dismutase (SOD), suggesting that specific modulation of ROS by probucol can restore EPC-mediated neovascularization.

Thymosins, a family of small proteins isolated from the calf thymus, have been shown to be involved in pathological conditions, such as wound healing, angiogenesis, and myocardial infarction $[114,115]$. Qiu et al. have studied the role of thymosin $\beta 4$ in EPC biology [116]. As in other studies, thymosin $\beta 4$-treated EPCs showed an enhanced migration ability. Thymosin $\beta 4$ stimulates Akt/eNOS phosphorylation and upregulates eNOS signaling in preconditioned EPCs; thymosin $\beta 4$ can also increase the survival ratio of transplanted EPCs via NO-mediated vascular tissue relaxation and augmented blood flow.

\section{Drug-Based Functional Improvement of Cytoprotective Mediators in EPCs}

Statins, cytoprotective mediators well known as 3-hydroxy3-methyl-glutaryl- (HMG-) CoA reductase inhibitors, are generally used for regulation of cholesterol levels in blood. Because of this lipid-lowering effect, statins are clinically used by patients with myocardial infarction [117], heart failure [118], vasospasms [119], diabetes [120], and hypertension [121]. The study on statin-treated EPCs by Vasa et al. revealed that a statin can improve EPC functional activities [122]. Although patients with CAD show a reduced number of CD34/KDR-positive cells, administration of atorvastatin to these patients leads to an increase in the $\mathrm{CD} 34^{+}-\mathrm{KDR}^{+}$ cell population, while there is no significant change in $\mathrm{CD} 4^{+}$or $\mathrm{CD} 33^{+}$cells. Migratory capacity of EPCs isolated from atorvastatin-treated patients with CVD is significantly augmented, as compared with EPCs from untreated patients. Those researchers also evaluated the serum cholesterol and cytokine levels, which are related to modulation of EPC mobilization or angiogenesis in vivo. Statin treatment did not alter serum levels of GM-CSF, TNF- $\alpha$, and VEGF, 
supporting the hypothesis that statin treatment stimulates the differentiation of endothelial precursor cells into EPCs, suggesting that statins directly enhance the EPC migration ability in patients with CAD.

Hydrogen sulfide $\left(\mathrm{H}_{2} \mathrm{~S}\right)$ was recently recognized as an important cytoprotective mediator in the cardiovascular system. This colorless and water-soluble gas is produced by catalytic reactions of L-cysteine. Downregulation of $\mathrm{H}_{2} \mathrm{~S}$ influences inflammation, circulatory shock, and reperfusion injury in various animal models [123]. For instance, db/db mice as a model of diabetes mellitus were used in studied on $\mathrm{H}_{2} \mathrm{~S}$-mediated diabetic-wound healing [124]. $\mathrm{H}_{2} \mathrm{~S}$ significantly stimulates the angiogenic function of EPCs via upregulation of angiopoietin-1 and the VEGF signaling pathway, as well as EPC-mediated wound healing.

eNOS, induced by phosphorylated Akt, generates NO. Released NO activates MMP-9 [125]. This enzyme cleaves mKitL and releases sKitL. Secreted c-Kit (sKitL) promotes cell survival and mobilization and proliferation of EPCs. NO is an essential cytoprotective mediator for cardiovascular homeostasis. This colorless gas inhibits contraction of vascular smooth muscle, platelet aggregation, and leukocyte adhesion to the endothelium. NO also inhibits EPC apoptosis but enhances cell proliferation and MMP9-mediated EPC mobilization [125]. Dysfunction of NO pathways in human is closely related to CVDs including atherosclerosis and hypertension and to diabetes. NO-derived neuronal NOS is well known as a mediator of vascular relaxation in the penis [126]. Erection of the penis is sustained by PI3K/Akt-dependent phosphorylation and activation of eNOS, an NO-producing enzyme [127].

\section{Promising EPC-Based Therapeutic Strategies against CVDs}

Because transplanted EPCs are facing the harsh environment of an injured tissue, including low oxygen concentration, ROS, an inflammatory attack, and nutrient insufficiency, clinical trials of transplanted EPC have yielded unsatisfactory outcomes [128]. In this section, we describe the recently proposed promising strategies for EPC-based cell therapy for severe ischemic CVDs.

6.1. Preconditioning of EPCs with Natural Compounds. Development of cell-priming protocols via preconditioning of EPCs may be promising therapeutic strategies for treatment of CVDs. Multiple research groups have attempted to develop novel therapeutic protocols on the basis of findings about cytoprotective mediators, pharmacologically qualified drugs [129], growth factors [130], natural compounds [131], and signal-related triggers for primed cells [132].

Fucoidan, a marine sulfated polysaccharide, is mainly found in extracts from brown algae and brown seaweed [133]. Many researchers have studied the therapeutic effects of fucoidan on osteoarthritis [134], cancer [135], diabetes [124], obesity [136], and kidney [137] and liver disease [138]. To overcome the replicative cellular senescence of isolated EPCs, Lee et al. tested the ability of fucoidan to rescue EPCs from senescence in vitro and its vascular repair capacity in vivo
[139]. EPCs briefly preconditioned with fucoidan caused a significant increase in the number of CD34 ${ }^{+} \mathrm{EPCs}, \mathrm{CXCR} 4^{+}$ EPCs, C-kit ${ }^{+}$EPCs, and VEGFR2 ${ }^{+}$EPCs. Notably, cellular senescence of EPCs is significantly attenuated by regulation of FAK-, Akt-, and ERK-related signaling cascades by fucoidantreated EPCs. In hindlimb ischemia models, a transplant of fucoidan-treated EPCs results in improved limb salvage with enhanced in vivo cell proliferation and cell survival in ischemic tissue.

Tripterine (celastrol) is extracted from the medicinal plant Tripterygium wilfordii. This quinone methide is used for treatment of rheumatoid arthritis in traditional Chinese medicine [140]. According to recent studies, tripterine has anticancer [141], antioxidant [142], and anti-inflammatory activities [143]. Lu et al. recently reported the efficacy of tripterine-treated EPCs against atherosclerosis [144]. In an in vitro culture assay, tripterine-priming EPCs showed enhanced adhesion, migration, proliferation, and tube formation, as well as a reduced apoptotic ratio during incubation with ox-LDL. By means of short-term priming of those cells with tripterine, the level of integrin-linked kinase (ILK) that is downregulated by ox-LDL is restored, whereas transfection with a silLK and dominant-negative ILK-expressing vector inhibits phosphorylation of ILK's downstream gene protein kinase $\mathrm{B}(\mathrm{PKB}) / \mathrm{Akt}$ and glycogen synthase kinase $3 \beta$ (GSK$3 \beta)$. When injected into atherosclerotic mice, tripterineprimed EPCs decrease aortic lesions and plaque deposition according to hematoxylin-eosin staining of aortic roots, suggesting that tripterine enhances EPC activity against atherosclerosis by means of the ILK signaling pathway.

Accumulating empirical evidence suggests that ovarian hormones such as estrogen and progesterone regulate angiogenesis $[145,146]$. Estrogens in women exist in three major forms: estrone (E1), estradiol (E2), and estriol (E3). The predominant form of estrogen during reproductive years is estradiol [147]. In vitro experiments revealed that estradiol induces EC proliferation [148] and migration [149] and reduces senescence [150]. In this regard, effect of resveratrol is investigated in EPC biology [151, 152]. This polyphenolic phytoalexin, extracted from grapes, has been reported to act as an estrogen receptor agonist [153]. In addition, it also has been reported to enhance expression and activity of eNOS in ECs [154]. When incubated with resveratrol, resveratrol-treated EPCs show increased number of EPCs and promoted EPC proliferation, adhesion, and migration, as well as increased VEGF production and induced vasculogenesis, suggesting that preconditioning of EPCs by resveratrol might be a promising therapeutic strategies for treatment of CVDs. Recently, Lee et al. clearly reported that genistein, an isoflavone derived from soybeans, has affinity for estrogen receptors and strongly improved the engraftment of transplanted EPCs in an acute myocardial ischemia models [155]. When pretreated with genistein, primed EPCs represent enhanced EPC migration and proliferation via increase of ILK, $\alpha$-parvin, and F-actin and phosphorylation of ERK 1/2 signaling, suggesting that pretreatment of EPCs with genistein prior to transplantation can improve the regenerative potential in ischemic tissues, providing a novel strategy in adult stem cell therapy for ischemic diseases. 
6.2. Genetic Modification of EPCs with Cytoprotective Modulators. To enhance EPC bioactivities, major efforts have been devoted to genetic modification of transplanted cells as a strategy against CVDs. In this subsection, we introduce recently reported cytoprotective mediators, angiotensinconverting-enzyme 2 (ACE2), insulin-like growth factor 1 (IGF-1), and integrin-linked kinase (ILK).

In the renin-angiotensin system, ACE2 converts angiotensin 1 into angiotensins $1-9$ and angiotensin 2 into angiotensins 1-7 [156,157]. With the increasing recognition of their importance in the renin-angiotensin system, ACE2-targeting therapeutic studies are still in progress [158]. The role of ACE2 in EPC function was studied by Chen et al. [159]. They isolated BM-derived EPCs from $\mathrm{R}^{+} \mathrm{A}^{+}$and $\mathrm{R}^{-} \mathrm{A}^{-}$mice and then infected these cells with a lentiviral system expressing the ACE2 gene. Overexpression of ACE2 in EPCs upregulates eNOS but downregulates Nox 2 and Nox4. Similarly, NO production by ACE2-transduced EPCs is greater than that of control EPCs. An in vitro functional assay and an in vivo study on a middle cerebral artery occlusion- (MCAO) induced stoke model further showed that ACE2 enhances EPC function via eNOS/NO and Nox/ROS signaling pathways.

A hormone structurally analogous to insulin, IGF-1, performs an important function in embryonic and postnatal development. Various processes in EPC biology such as cell proliferation, migration, and incorporation are influenced by IGF-1 [160]. Sen et al. genetically modified EPCs with IGF1 gene-carrying AAV systems and transplanted EPCs into a rat model of myocardial infraction [161]. Compared to LacZEPCs, IGF-1-transduced EPCs yield increased cardiomyocyte proliferation and a greater capillary number in the periinfarct area with a reduced cardiac apoptosis rate, indicating that genetic modification of EPCs by the IGF-1-AAV delivery system may be an effective tool for EPC-based cell therapy.

Several researchers have targeted integrin-linked kinase (ILK) for genetic modification of EPCs as a strategy against CVDs, because integrins are located in the cell membrane and regulate cell migration, survival, proliferation, and differentiation. ILK has also been reported to serve as a key regulator of actin rearrangement, cell polarization, spreading on a substrate, migration, proliferation, and survival [162]. Wang et al. generated ILK gene-transduced EPCs from subjects with preeclampsia and studied the possible effects of the modified EPCs against CVDs. ILK-overexpressing EPCs showed enhanced bioactivities including cell proliferation, migration, and in vivo EPC-mediated neovascularization, revealing a good potential for an EPC-based gene therapy in patients with preeclampsia [163].

6.3. Strategies for a Combinatorial EPC Cell Therapy. Development of a combinatorial cell therapy using multiple stem cells might be a promising treatment strategy, because various adult stem cells have unique cell lineage determination, offering synergistic effects on cell-based-neovascularization against CVDs.

To develop cell hybrid therapeutic strategies, Lee et al. studied the functional properties of two types of EPCs [164]: CD34 ${ }^{-} / \mathrm{CD} 34^{+}$cell-derived ECFCs (hybrid-dECFCs) and CD $34^{+}$cell-derived ECFCs (stem-dECFC) [44]. HybriddECFCs showed remarkably enhanced bioactivities such as greater proliferative properties but delayed senescence. In an in vivo mouse model of hindlimb ischemia, hybrid-dECFCs showed significantly improved blood perfusion, capillary density, and improved cell survival and proliferation. Particularly, hybrid-dECFCs migration is significantly enhanced via an augmented phosphorylation cascade of focal adhesion kinase (FAK) [165] and Src [155] and consequently results in enhanced incorporation capacity of hybrid-dECFCs, suggesting that the $\mathrm{CD} 34^{-}$accessory cells may serve as nichesupporting cells during formation of $\mathrm{CD} 4^{+}$cell-derived EPCs.

Zigdon-Giladi et al. recently reported the effects of EPCs in combination with MSCs on bone regeneration [166]. Osteogenically transformed MSCs and EPCs were seeded into gold domes and mixed with a $\beta$-tricalcium phosphate ( $\beta$ TCP) scaffold [167]. Rats with the transplant of the EPC/MSC hybrid cells show increased blood vessel density, vertical bone height, and bone area in the regenerated tissue. Although the groups 4 weeks after transplant had similar characteristics for control and EPC/MSC treatment, the above parameters were doubled in the EPC/MSC hybrid transplant group at 12 weeks after transplant, suggesting that the EPC/MSC hybrid transplant increases blood vessel formation at early stages and enhances bone regeneration at later stages.

Kang et al. attempted to enhance islet engraftment by cotransplanting EPCs with islets [25]. Porcine islets and human cord blood-derived EPCs were cotransplanted into diabetic nude mice [168]. At 11 days after transplant, the islet/ EPC group reached euglycemia [169], in contrast to the isletonly group. Insulin levels were found to be higher in the islet/ EPC group than in the islet-only group, pointing to rapid revascularization with a VEGF-A-dependent enhanced perfusion ratio. Cell proliferation of $\beta$-cells is also increased by hepatocyte growth factor, indicating that an islet/EPC transplant may be an efficient therapeutic strategy against diabetes [170].

6.4. EPC-Mediated Secretome and Paracrine Effects on Cardiovascular Regeneration. EPCs contribute to cardiovascular regeneration indirectly via secreting tremendous secretomes, including microvesicles (MVs), cytokines, and chemokines, including VEGF, basic FGF, and IGF [171]. These secretomes or cytokines affect itself (autocrine) or other cells (paracrine) [172].

Previously, it has been reported that EPC-conditioned media have cardioprotective role in MI [173]. In addition, soluble factors from EPCs enhance cell function and promote cardiovascular regeneration [174]. Recent study reveals that proteinaceous and nonproteinaceous factors are involved in EPC-mediated cytoprotective role on ischemic insult in brain [175].

In cell-to-cell communication, diverse types of cells secrete microvesicles (MVs) in response to different stimuli from environmental condition [176]. Interestingly, pivotal proteins and RNAs (mRNA, miRNA) are capable of transporting to target cells via MVs. To investigate the role of 


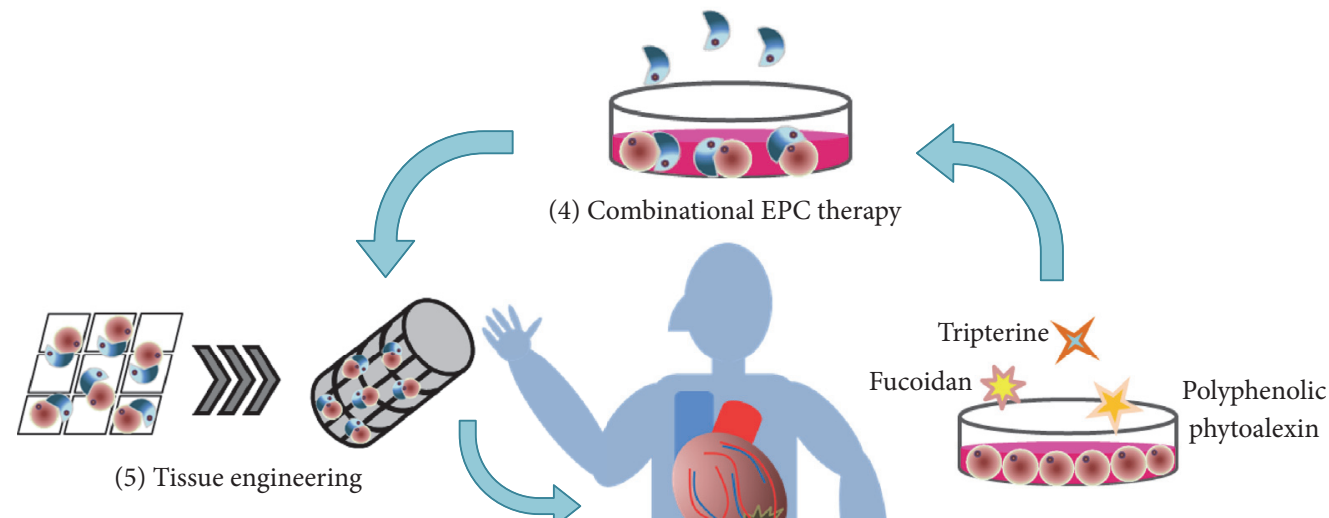

(6) Transplantation

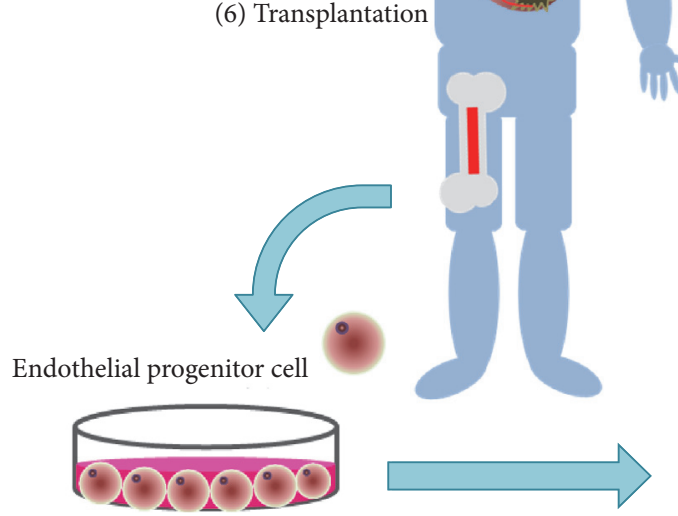

(3) Preconditioning

(1) Primary culture

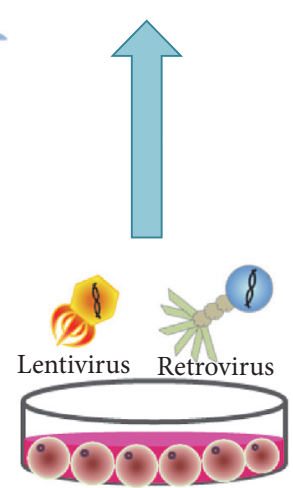

(2) Genetic modification

FIGURE 2: Promising therapeutic strategies for EPC therapy. Multistep combinational therapeutic strategies of EPC therapy against CVDs include the following: (1) patient-derived EPCs are isolated from healthy tissue; ((2), (3), (4)) improvement in EPC bioactivities via genetic modifications or pretreatment with natural compound or cocultured with other stem cells, such as MSCs and CPCs; and ((5), (6)) tissue engineering techniques using biomaterials protect cells from the harsh conditions of ischemic regions.

EPC-derived MVs on cardiac hypertrophy and apoptosis, $\mathrm{Gu}$ et al. evaluated Ang II-induced cardiomyocyte (CM) hypertrophy and apoptosis in condition of with or without EPC-MVs [177]. Similar to previous report from EPC-MVs effects on angiogenesis [178], EPC-MVs strongly promote vascularization via effective incorporation into $\mathrm{CM}$, resulting in decreased hypertrophy and apoptosis rate. Importantly, ROS overproduction induced by Ang II was significantly decreased in MVs-CM via regulation PI3K/Akt/eNOS pathway [179].

6.5. Tissue Engineering Strategies to Facilitate EPC-Mediated Neovascularization. To improve EPC function, continuous efforts of investigators recently provided novel therapeutic strategies involving biocompatible biomaterials such as metallic compounds, polymers, and composite materials against CVDs [180].

To prevent the complications such as local thrombus formation and restenosis, Shirota et al. fabricated two types of EPC-seeded intravascular stent devices [181]. A photocured gelatin-coated metallic stent and a photocured gelatincoated microporous thin segmented polyurethane (SPU) film-covered stent were used in this experiment with a confluent monolayer of seeded EPC $[182,183]$. Tubular hybrid vascular medial tissue, composed of vascular smooth muscle cells and collagen, was filled with expanded EPCs. Migrating EPCs from the stent struts proliferated and endothelialized the luminal surface of the hybrid vascular medial tissue [184]. On-stent delivery EPCs may be a novel therapeutic approach to reconstitution of the atherosclerotic arterial wall with various benefits, prevention of thrombosis and restenosis [185], and promotion of rapid formation of normal tissue architecture.

Peters et al. reported efficacy of hydrogel scaffolds in terms of EPC-mediated neovascularization [186]. This biomaterial consists of a cell-adhesive and proteolytically degradable polyethylene glycol hydrogel [187]. EPCs are cocultured with angiogenic mural cells (SMCs) in encapsulated hydrogel scaffolds. Polymeric precursors were mixed with the cells, and then a mild photo-cross-linking procedure was performed [188]. Without additional cytokines, EPCs formed a 3D microvessel network. After 2 weeks of coculture, those investigators observed 3D-EPC microvessels, suggesting that initiating custom hydrogels may support formation of diverse microvessels.

\section{Future Directions}

Given the increasing life expectancy, prevention and management of CVDs in humans are necessary. In the human 
body, the blood circulation system is omnipresent and connects different tissues. To recover injured vessels, the understanding of pathophysiological niche components and their supporting cells including stem/progenitor cells is crucial. In terms of EPC-based cell therapy, it may useful to screen the promising cytoprotective mediators in experiments on EPC biology. Specific target molecules are prestimulated by natural products, with a genetic modification, or tissue engineering technologies to promote cell-ECM interactions for better EPC bioactivities, before a transplant into an ischemic tissue. Due to their complexity, EPC-based regeneration strategies should be integrated; this way, they will still have a tremendous regenerative potential in CVDs. Further experiments on EPC-based therapeutic strategies can open up more promising opportunities, where a combination of multiple strategies may improve EPC bioactivities including cellular proliferation, survival, and in vivo differentiation (Figure 2).

\section{Competing Interests}

The authors declare that they do not have any conflict of interests.

\section{Authors' Contributions}

Hyunyun Kim and Sujin Kim contributed equally to this study.

\section{Acknowledgments}

This work was supported by a grant from the National Research Foundation (NRF-2015M3A9B4051053, NRF2015M3A9B4066493, NRF-2015R1A5A2009656, NRF2014R1A1 A2056907, and NRF-2014R1A2A1A11052311) and Brain Busan 21 (BB21) program.

\section{References}

[1] D. S. Ludwig, M. A. Pereira, C. H. Kroenke et al., "Dietary fiber, weight gain, and cardiovascular disease risk factors in young adults," Journal of the American Medical Association, vol. 282, no. 16, pp. 1539-1546, 1999.

[2] WHO, Diet, Nutrition and the Prevention of Chronic Diseases, WHO Technical Report Series, WHO, Geneva, Switzerland, 2003.

[3] S. Kanzler, C. Hartmann, A. Gruber, G. Lammer, and K.-H. Wagner, "Salt as a public health challenge in continental European convenience and ready meals," Public Health Nutrition, vol. 17, no. 11, pp. 2459-2466, 2014.

[4] K. Oh, F. B. Hu, J. E. Manson, M. J. Stampfer, and W. C. Willett, "Dietary fat intake and risk of coronary heart disease in women: 20 years of follow-up of the nurses' health study," American Journal of Epidemiology, vol. 161, no. 7, pp. 672-679, 2005.

[5] B. V. Howard and J. Wylie-Rosett, "Sugar and cardiovascular disease: a statement for healthcare professionals from the committee on nutrition of the council on nutrition, physical activity, and metabolism of the american heart association," Circulation, vol. 106, no. 4, pp. 523-527, 2002.

[6] P. G. Guyenet, "The sympathetic control of blood pressure," Nature Reviews Neuroscience, vol. 7, no. 5, pp. 335-346, 2006.
[7] J. Abrams, "Chronic stable angina," The New England Journal of Medicine, vol. 352, no. 24, pp. 2524-2533, 2005.

[8] K. Thygesen, J. S. Alpert, A. S. Jaffe, M. L. Simoons, B. R. Chaitman, and H. D. White, "Third universal definition of myocardial infarction," Nature Reviews Cardiology, vol. 9, no. 11, pp. 620633, 2012

[9] B. P. Delisle, B. D. Anson, S. Rajamani, and C. T. January, "Biology of cardiac arrhythmias: ion channel protein trafficking," Circulation Research, vol. 94, no. 11, pp. 1418-1428, 2004.

[10] J. R. Sowers, M. Epstein, and E. D. Frohlich, "Diabetes, hypertension, and cardiovascular disease an update," Hypertension, vol. 37, no. 4, pp. 1053-1059, 2001.

[11] D. T. Giacobbe and M. J. Murray, "Vascular disease and inflammation," Anesthesiology Clinics of North America, vol. 22, no. 2, pp. 183-197, 2004.

[12] J. F. Bentzon, F. Otsuka, R. Virmani, and E. Falk, "Mechanisms of plaque formation and rupture," Circulation Research, vol. 114, no. 12, pp. 1852-1866, 2014.

[13] I. Tabas, G. García-Cardeña, and G. K. Owens, "Recent insights into the cellular biology of atherosclerosis," Journal of Cell Bio$\log y$, vol. 209, no. 1, pp. 13-22, 2015.

[14] E. G. Nabel, “Cardiovascular disease," The New England Journal of Medicine, vol. 349, no. 1, pp. 60-72, 2003.

[15] N. Smart and P. R. Riley, "The stem cell movement," Circulation Research, vol. 102, no. 10, pp. 1155-1168, 2008.

[16] R. C. Rennert, M. Sorkin, R. K. Garg, and G. C. Gurtner, "Stem cell recruitment after injury: lessons for regenerative medicine," Regenerative Medicine, vol. 7, no. 6, pp. 833-850, 2012.

[17] L. Tilling, P. Chowienczyk, and B. Clapp, "Progenitors in motion: mechanisms of mobilization of endothelial progenitor cells," British Journal of Clinical Pharmacology, vol. 68, no. 4, pp. 484-492, 2009.

[18] L. Huang, F. Wang, Y. Wang et al., "Acidic fibroblast growth factor promotes endothelial progenitor cells function via Akt/FOXO3 $\alpha$ pathway," PLoS ONE, vol. 10, no. 6, Article ID e0129665, 2015.

[19] F. Caiado and S. Dias, "Endothelial progenitor cells and integrins: adhesive needs," Fibrogenesis \& Tissue Repair, vol. 5 article 4, 2012.

[20] S. P. Yu, Z. Wei, and L. Wei, "Preconditioning strategy in stem cell transplantation therapy," Translational Stroke Research, vol. 4, no. 1, pp. 76-88, 2013.

[21] S. P. Goff, "Host factors exploited by retroviruses," Nature Reviews Microbiology, vol. 5, no. 4, pp. 253-263, 2007.

[22] T. Sakuma, M. A. Barry, and Y. Ikeda, "Lentiviral vectors: basic to translational," Biochemical Journal, vol. 443, no. 3, pp. 603618, 2012.

[23] S. Daya and K. I. Berns, "Gene therapy using adeno-associated virus vectors," Clinical Microbiology Reviews, vol. 21, no. 4, pp. 583-593, 2008.

[24] H. Zigdon-Giladi, T. Bick, D. Lewinson, and E. E. Machtei, "Co-transplantation of endothelial progenitor cells and mesenchymal stem cells promote neovascularization and bone regeneration," Clinical Implant Dentistry and Related Research, vol. 17, no. 2, pp. 353-359, 2015.

[25] S. Kang, H. S. Park, A. Jo et al., "Endothelial progenitor cell cotransplantation enhances islet engraftment by rapid revascularization," Diabetes, vol. 61, no. 4, pp. 866-876, 2012.

[26] B. B. Ratliff, T. Ghaly, P. Brudnicki et al., "Endothelial progenitors encapsulated in bioartificial niches are insulated from systemic cytotoxicity and are angiogenesis competent," American 
Journal of Physiology - Renal Physiology, vol. 299, no. 1, pp. F178F186, 2010.

[27] S. Hinderer, S. L. Layland, and K. Schenke-Layland, "ECM and ECM-like materials-biomaterials for applications in regenerative medicine and cancer therapy," Advanced Drug Delivery Reviews, vol. 97, pp. 260-269, 2016.

[28] T. Asahara, T. Murohara, A. Sullivan et al., "Isolation of putative progenitor endothelial cells for angiogenesis," Science, vol. 275, no. 5302, pp. 964-967, 1997.

[29] T. Asahara, T. Takahashi, H. Masuda et al., "VEGF contributes to postnatal neovascularization by mobilizing bone marrow-derived endothelial progenitor cells," EMBO Journal, vol. 18, no. 14, pp. 3964-3972, 1999.

[30] M. Peichev, A. J. Naiyer, D. Pereira et al., "Expression of VEGFR2 and AC133 by circulating human CD34+ cells identifies a population of functional endothelial precursors," Blood, vol. 95, no. 3, pp. 952-958, 2000.

[31] Y.-N. Liu, J. Zhang, Q.-H. He, X. Dai, and L. Shen, "Isolation and characterization of epithelial progenitor cells from human fetal liver," Hepatology Research, vol. 38, no. 1, pp. 103-113, 2008.

[32] T. Tamaki, A. Akatsuka, K. Ando et al., "Identification of myogenic-endothelial progenitor cells in the interstitial spaces of skeletal muscle," Journal of Cell Biology, vol. 157, no. 4, pp. 571577, 2002.

[33] A. Aicher, A. M. Zeiher, and S. Dimmeler, "Mobilizing endothelial progenitor cells," Hypertension, vol. 45, no. 3, pp. 321-325, 2005.

[34] N. Werner and G. Nickenig, "Clinical and therapeutical implications of EPC biology in atherosclerosis," Journal of Cellular and Molecular Medicine, vol. 10, no. 2, pp. 318-332, 2006.

[35] S. Taghavi and J. C. George, "Homing of stem cells to ischemic myocardium," American Journal of Translational Research, vol. 5, no. 4, pp. 404-411, 2013.

[36] V. W. Wong and J. D. Crawford, "Vasculogenic cytokines in wound healing," BioMed Research International, vol. 2013, Article ID 190486, 11 pages, 2013.

[37] G. O. Ouma, B. Zafrir, E. R. Mohler, and M. Y. Flugelman, "Therapeutic angiogenesis in critical limb Ischemia," Angiology, vol. 64, no. 6, pp. 466-480, 2013.

[38] M. Furuya, M. Nishiyama, Y. Kasuya, S. Kimura, and H. Ishikura, "Pathophysiology of tumor neovascularization," Vascular Health and Risk Management, vol. 1, no. 4, pp. 277-290, 2005.

[39] D. S. Krause, M. J. Fackler, C. I. Civin, and W. S. May, "CD34: structure, biology, and clinical utility," Blood, vol. 87, no. 1, pp. 1-13, 1996.

[40] C. Urbich and S. Dimmeler, "Endothelial progenitor cells: functional characterization," Trends in Cardiovascular Medicine, vol. 14, no. 8, pp. 318-322, 2004.

[41] A.-K. Olsson, A. Dimberg, J. Kreuger, and L. Claesson-Welsh, "VEGF receptor signalling-in control of vascular function," Nature Reviews Molecular Cell Biology, vol. 7, no. 5, pp. 359-371, 2006.

[42] D. Mizrak, M. Brittan, and M. R. Alison, "CD133: molecule of the moment," Journal of Pathology, vol. 214, no. 1, pp. 3-9, 2008.

[43] M. C. Yoder, "Human endothelial progenitor cells," Cold Spring Harbor Perspectives in Medicine, vol. 2, no. 7, Article ID a006692, 2012.

[44] M. Hristov, W. Erl, and P. C. Weber, "Endothelial progenitor cells," Arteriosclerosis, Thrombosis, and Vascular Biology, vol. 23, no. 7, pp. 1185-1189, 2003.
[45] Y. Lin, D. J. Weisdorf, A. Solovey, and R. P. Hebbel, "Origins of circulating endothelial cells and endothelial outgrowth from blood," Journal of Clinical Investigation, vol. 105, no. 1, pp. 71-77, 2000.

[46] Q. Shi, S. Rafii, M. Wu Hong-De et al., "Evidence for circulating bone marrow-derived endothelial cells," Blood, vol. 92, no. 2, pp. 362-367, 1998.

[47] C. Schmidt-Lucke, L. Rössig, S. Fichtlscherer et al., "Reduced number of circulating endothelial progenitor cells predicts future cardiovascular events: proof of concept for the clinical importance of endogenous vascular repair," Circulation, vol. 111, no. 22, pp. 2981-2987, 2005.

[48] K. E. Jie, M. R. Lilien, M. H. J. Goossens, P. E. Westerweel, M. Klein, and M. C. Verhaar, "Reduced endothelial progenitor cells in children with hemodialysis but not predialysis chronic kidney disease," Pediatrics, vol. 126, no. 4, p. 3346, 2010.

[49] A. S. Levey and J. Coresh, "Chronic kidney disease," The Lancet, vol. 379, no. 9811, pp. 165-180, 2012.

[50] K. Herbrig, F. Pistrosch, S. Foerster, and P. Gross, "Endothelial progenitor cells in chronic renal insufficiency," Kidney and Blood Pressure Research, vol. 29, no. 1, pp. 24-31, 2006.

[51] G. K. Hansson, "Inflammation, atherosclerosis, and coronary artery disease," New England Journal of Medicine, vol. 352, no. 16, pp. 1685-1695, 2005.

[52] T. Eizawa, U. Ikeda, Y. Murakami et al., "Decrease in circulating endothelial progenitor cells in patients with stable coronary artery disease," Heart, vol. 90, no. 6, pp. 685-686, 2004.

[53] M. L. Hermiston, Z. Xu, and A. Weiss, "CD45: a critical regulator of signaling thresholds in immune cells," Annual Review of Immunology, vol. 21, pp. 107-137, 2003.

[54] C. Fischer, M. Mazzone, B. Jonckx, and P. Carmeliet, "FLT1 and its ligands VEGFB and PlGF: drug targets for anti-angiogenic therapy?” Nature Reviews Cancer, vol. 8, no. 12, pp. 942-956, 2008.

[55] D. M. Dudzinski and T. Michel, "Life history of eNOS: partners and pathways," Cardiovascular Research, vol. 75, no. 2, pp. 247260, 2007.

[56] P. J. Lenting, C. Casari, O. D. Christophe, and C. V. Denis, "von Willebrand factor: the old, the new and the unknown," Journal of Thrombosis and Haemostasis, vol. 10, no. 12, pp. 2428-2437, 2012.

[57] A. Woodfin, M.-B. Voisin, and S. Nourshargh, "PECAM-1: a multi-functional molecule in inflammation and vascular biology," Arteriosclerosis, Thrombosis, and Vascular Biology, vol. 27, no. 12, pp. 2514-2523, 2007.

[58] N. Ferrara, H.-P. Gerber, and J. LeCouter, “The biology of VEGF and its receptors," Nature Medicine, vol. 9, no. 6, pp. 669-676, 2003.

[59] B. Baudin, A. Bruneel, N. Bosselut, and M. Vaubourdolle, "A protocol for isolation and culture of human umbilical vein endothelial cells," Nature Protocols, vol. 2, no. 3, pp. 481-485, 2007.

[60] H. W. L. Ziegler-Heitbrock and R. J. Ulevitch, "CD14: cell surface receptor and differentiation marker," Immunology Today, vol. 14, no. 3, pp. 121-125, 1993.

[61] T. J. Povsic, K. L. Zavodni, E. Vainorius, J. F. Kherani, P. J. Goldschmidt-Clermont, and E. D. Peterson, "Common endothelial progenitor cell assays identify discrete endothelial progenitor cell populations," American Heart Journal, vol. 157, no. 2, pp. 335-344, 2009. 
[62] A. Harada, N. Sekido, T. Akahoshi, T. Wada, N. Mukaida, and K. Matsushima, "Essential involvement of interleukin-8 (IL-8) in acute inflammation," Journal of Leukocyte Biology, vol. 56, no. 5, pp. 559-564, 1994.

[63] C. J. Eaves, "Hematopoietic stem cells: concepts, definitions, and the new reality," Blood, vol. 125, no. 17, pp. 2605-2613, 2015.

[64] S.-M. Kwon, Y.-K. Lee, A. Yokoyama et al., "Differential activity of bone marrow hematopoietic stem cell subpopulations for EPC development and ischemic neovascularization," Journal of Molecular and Cellular Cardiology, vol. 51, no. 3, pp. 308-317, 2011.

[65] L. K. Ashman, "The biology of stem cell factor and its receptor C-kit," International Journal of Biochemistry and Cell Biology, vol. 31, no. 10, pp. 1037-1051, 1999.

[66] R. Gulati, D. Jevremovic, T. E. Peterson et al., "Diverse origin and function of cells with endothelial phenotype obtained from adult human blood," Circulation Research, vol. 93, no. 11, pp. 1023-1025, 2003.

[67] C. Holmes and W. L. Stanford, "Concise review: stem cell antigen-1: expression, function, and enigma," Stem Cells, vol. 25, no. 6, pp. 1339-1347, 2007.

[68] J. E. Grove, E. Bruscia, and D. S. Krause, "Plasticity of bone marrow-derived stem cells," Stem Cells, vol. 22, no. 4, pp. 487500, 2004.

[69] T. Yin and L. Li, “The stem cell niches in bone," The Journal of Clinical Investigation, vol. 116, no. 5, pp. 1195-1201, 2006.

[70] P. L. Doan and J. P. Chute, “The vascular niche: home for normal and malignant hematopoietic stem cells," Leukemia, vol. 26, no. 1, pp. 54-62, 2012.

[71] H.-G. Kopp, S. T. Avecilla, A. T. Hooper, and S. Rafii, "The bone marrow vascular niche: home of HSC differentiation and mobilization," Physiology, vol. 20, no. 5, pp. 349-356, 2005.

[72] F. Arai, A. Hirao, M. Ohmura et al., “Tie2/angiopoietin-1 signaling regulates hematopoietic stem cell quiescence in the bone marrow niche," Cell, vol. 118, no. 2, pp. 149-161, 2004.

[73] J.-P. Lévesque, F. M. Helwani, and I. G. Winkler, “The endosteal 'osteoblastic' niche and its role in hematopoietic stem cell homing and mobilization," Leukemia, vol. 24, no. 12, pp. 19791992, 2010.

[74] T. Itkin and T. Lapidot, "SDF-1 keeps HSC quiescent at home," Blood, vol. 117, no. 2, pp. 373-374, 2011.

[75] J. M. Weber and L. M. Calvi, "Notch signaling and the bone marrow hematopoietic stem cell niche," Bone, vol. 46, no. 2, pp. 281285, 2010.

[76] R. E. Verloop, P. Koolwijk, A. J. Van Zonneveld, and V. W. M. Van Hinsbergh, "Proteases and receptors in the recruitment of endothelial progenitor cells in neovascularization," European Cytokine Network, vol. 20, no. 4, pp. 207-219, 2009.

[77] B. Heissig, K. Hattori, S. Dias et al., "Recruitment of stem and progenitor cells from the bone marrow niche requires MMP-9 mediated release of Kit-ligand," Cell, vol. 109, no. 5, pp. 625-637, 2002.

[78] J. S. Mumm and R. Kopan, "Notch signaling: from the outside in," Developmental Biology, vol. 228, no. 2, pp. 151-165, 2000.

[79] S. Chiba, "Concise review: notch signaling in stem cell systems," Stem Cells, vol. 24, no. 11, pp. 2437-2447, 2006.

[80] S.-M. Kwon, M. Eguchi, M. Wada et al., "Specific jagged-1 signal from bone marrow microenvironment is required for endothelial progenitor cell development for neovascularization," Circulation, vol. 118, no. 2, pp. 157-165, 2008.
[81] S. J. C. Mancini, N. Mantei, A. Dumortier, U. Suter, H. R. MacDonald, and F. Radtke, "Jagged1-dependent Notch signaling is dispensable for hematopoietic stem cell self-renewal and differentiation," Blood, vol. 105, no. 6, pp. 2340-2342, 2005.

[82] S. Takaki, K. Sauer, B. M. Iritani et al., "Control of B cell production by the adaptor protein Lnk: definition of a conserved family of signal-modulating proteins," Immunity, vol. 13, no. 5, pp. 599-609, 2000.

[83] H. Ema, K. Sudo, J. Seita et al., "Quantification of self-renewal capacity in single hematopoietic stem cells from normal and Lnk-deficient mice," Developmental Cell, vol. 8, no. 6, pp. 907914, 2005.

[84] S.-M. Kwon, T. Suzuki, A. Kawamoto et al., "Pivotal role of lnk adaptor protein in endothelial progenitor cell biology for vascular regeneration," Circulation Research, vol. 104, no. 8, pp. 969-977, 2009.

[85] T. Takahashi, C. Kalka, H. Masuda et al., "Ischemia- and cytokine-induced mobilization of bone marrow-derived endothelial progenitor cells for neovascularization," Nature Medicine, vol. 5, no. 4, pp. 434-438, 1999.

[86] R. K. Root and D. C. Dale, "Granulocyte colony-stimulating factor and granulocyte-macrophage colony-stimulating factor: comparisons and potential for use in the treatment of infections in nonneutropenic patients," Journal of Infectious Diseases, vol. 179, no. 2, pp. S342-S352, 1999.

[87] Y. Fan, J. Ye, F. Shen et al., "Interleukin-6 stimulates circulating blood-derived endothelial progenitor cell angiogenesis in vitro," Journal of Cerebral Blood Flow and Metabolism, vol. 28, no. 1, pp. 90-98, 2008.

[88] L. M. Ellis and D. J. Hicklin, "VEGF-targeted therapy: mechanisms of anti-tumour activity," Nature Reviews Cancer, vol. 8, no. 8, pp. 579-591, 2008.

[89] Q. Ke and M. Costa, "Hypoxia-inducible factor-1 (HIF-1)," Molecular Pharmacology, vol. 70, no. 5, pp. 1469-1480, 2006.

[90] J. A. Forsythe, B.-H. Jiang, N. V. Iyer et al., "Activation of vascular endothelial growth factor gene transcription by hypoxiainducible factor 1," Molecular and Cellular Biology, vol. 16, no. 9, pp. 4604-4613, 1996.

[91] P. De La Puente, B. Muz, F. Azab, and A. K. Azab, "Cell trafficking of endothelial progenitor cells in tumor progression," Clinical Cancer Research, vol. 19, no. 13, pp. 3360-3368, 2013.

[92] R. N. Kaplan, B. Psaila, and D. Lyden, "Niche-to-niche migration of bone-marrow-derived cells," Trends in Molecular Medicine, vol. 13, no. 2, pp. 72-81, 2007.

[93] A. T. Askari, S. Unzek, Z. B. Popovic et al., "Effect of stromalcell-derived factor 1 on stem-cell homing and tissue regeneration in ischaemic cardiomyopathy," The Lancet, vol. 362, no. 9385, pp. 697-703, 2003.

[94] Y.-F. Li, L.-N. Ren, G. Guo et al., "Endothelial progenitor cells in ischemic stroke: an exploration from hypothesis to therapy," Journal of Hematology and Oncology, vol. 8, article 33, 2015.

[95] C. Cencioni, M. C. Capogrossi, and M. Napolitano, "The SDF1/CXCR4 axis in stem cell preconditioning," Cardiovascular Research, vol. 94, no. 3, pp. 400-407, 2012.

[96] T. K. Ho, X. Shiwen, D. Abraham, J. Tsui, and D. Baker, "Stromal-cell-derived factor-1 (SDF-1)/CXCL12 as potential target of therapeutic angiogenesis in critical leg ischaemia," Cardiology Research and Practice, vol. 2012, Article ID 143209, 7 pages, 2012.

[97] T.-J. Lin, T. B. Issekutz, and J. S. Marshall, "SDF-1 induces IL8 production and transendothelial migration of human cord 
blood-derived mast cells," International Archives of Allergy and Immunology, vol. 124, no. 1-3, pp. 142-145, 2001.

[98] X. Pi, Y. Wu, J. E. Ferguson III, A. L. Portbury, and C. Patterson, "SDF-1 $\alpha$ stimulates JNK3 activity via eNOS-dependent nitrosylation of MKP7 to enhance endothelial migration," Proceedings of the National Academy of Sciences of the United States of America, vol. 106, no. 14, pp. 5675-5680, 2009.

[99] Y. Takabatake, T. Sugiyama, H. Kohara et al., "The CXCL12 (SDF-1)/CXCR4 axis is essential for the development of renal vasculature," Journal of the American Society of Nephrology, vol. 20, no. 8, pp. 1714-1723, 2009.

[100] C. Urbich and S. Dimmeler, "Endothelial progenitor cells: characterization and role in vascular biology," Circulation Research, vol. 95, no. 4, pp. 343-353, 2004.

[101] E. Galkina and K. Ley, "Vascular adhesion molecules in atherosclerosis," Arteriosclerosis, Thrombosis, and Vascular Biology, vol. 27, no. 11, pp. 2292-2301, 2007.

[102] I.-Y. Oh, C.-H. Yoon, J. Hur et al., "Involvement of E-selectin in recruitment of endothelial progenitor cells and angiogenesis in ischemic muscle," Blood, vol. 110, no. 12, pp. 3891-3899, 2007.

[103] Y. Wu, J. E. Ip, J. Huang et al., "Essential role of ICAM-1/CD18 in mediating EPC recruitment, angiogenesis, and repair to the infarcted myocardium," Circulation Research, vol. 99, no. 3, pp. 315-322, 2006.

[104] M. D. Silverman, C. S. Haas, A. M. Rad, A. S. Arbab, and A. E. Koch, "The role of vascular cell adhesion molecule 1/very late activation antigen 4 in endothelial progenitor cell recruitment to rheumatoid arthritis synovium," Arthritis and Rheumatism, vol. 56, no. 6, pp. 1817-1826, 2007.

[105] P.-H. Huang, Y.-H. Chen, C.-H. Wang et al., "Matrix metalloproteinase- 9 is essential for ischemia-induced neovascularization by modulating bone marrow-derived endothelial progenitor Cells," Arteriosclerosis, Thrombosis, and Vascular Biology, vol. 29, no. 8, pp. 1179-1184, 2009.

[106] C. Urbich, C. Heeschen, A. Aicher et al., "Cathepsin L is required for endothelial progenitor cell-induced neovascularization," Nature Medicine, vol. 11, no. 2, pp. 206-213, 2005.

[107] S. Fujiyama, K. Amano, K. Uehira et al., "Bone marrow monocyte lineage cells adhere on injured endothelium in a monocyte chemoattractant protein-1-dependent manner and accelerate reendothelialization as endothelial progenitor cells," Circulation Research, vol. 93, no. 10, pp. 980-989, 2003.

[108] D. H. Walter, K. Rittig, F. H. Bahlmann et al., "Statin therapy accelerates reendothelialization," Circulation, vol. 105, no. 25, pp. 3017-3024, 2002.

[109] L. Li, X. Chen, W. E. Wang, and C. Zeng, "How to improve the survival of transplanted mesenchymal stem cell in ischemic heart?" Stem Cells International, vol. 2016, Article ID 9682757, 14 pages, 2016.

[110] I. Shiojima and K. Walsh, "Role of Akt signaling in vascular homeostasis and angiogenesis," Circulation Research, vol. 90, no. 12, pp. 1243-1250, 2002.

[111] J. Hur, C.-H. Yoon, C.-S. Lee et al., "Akt is a key modulator of endothelial progenitor cell trafficking in ischemic muscle," Stem Cells, vol. 25, no. 7, pp. 1769-1778, 2007.

[112] N. R. Madamanchi, A. Vendrov, and M. S. Runge, "Oxidative stress and vascular disease," Arteriosclerosis, Thrombosis, and Vascular Biology, vol. 25, no. 1, pp. 29-38, 2005.

[113] Q. Zhang, L. Chen, Z. Si et al., "Probucol protects endothelial progenitor cells against oxidized low-density lipoprotein via suppression of reactive oxygen species formation in vivo,"
Cellular Physiology and Biochemistry, vol. 39, no. 1, pp. 89-101, 2016.

[114] K. M. Malinda, G. S. Sidhu, H. Mani et al., “Thymosin $\beta 4$ accelerates wound healing," Journal of Investigative Dermatology, vol. 113 , no. 3, pp. 364-368, 1999.

[115] N. Smart, S. Bollini, K. N. Dubé et al., "De novo cardiomyocytes from within the activated adult heart after injury," Nature, vol. 474, no. 7353, pp. 640-644, 2011.

[116] F.-Y. Qiu, X.-X. Song, H. Zheng, Y.-B. Zhao, and G.-S. Fu, “Thymosin $\beta 4$ induces endothelial progenitor cell migration via PI3K/Akt/eNOS signal transduction pathway," Journal of Cardiovascular Pharmacology, vol. 53, no. 3, pp. 209-214, 2009.

[117] U. Stenestrand and L. Wallentin, "Early statin treatment following acute myocardial infarction and 1-year survival," Journal of the American Medical Association, vol. 285, no. 4, pp. 430-436, 2001.

[118] J. Kjekshus, T. R. Pedersen, A. G. Olsson, O. Faergeman, and K. Pyorala, "The effects of simvastatin on the incidence of heart failure in patients with coronary heart disease," Journal of Cardiac Failure, vol. 3, no. 4, pp. 249-254, 1997.

[119] M. D. I. Vergouwen, R. J. De Haan, M. Vermeulen, and Y. B. W. E. M. Roos, "Effect of statin treatment on vasospasm, delayed cerebral ischemia, and functional outcome in patients with aneurysmal subarachnoid hemorrhage," Stroke, vol. 41, no. 1, pp. e47-e52, 2010.

[120] J. Buse, "Statin treatment in diabetes mellitus," Clinical Diabetes, vol. 21, no. 4, pp. 168-172, 2003.

[121] M. P. Schneider, B. M. Schmidt, S. John, and R. E. Schmieder, "Effects of statin treatment on endothelial function, oxidative stress and inflammation in patients with arterial hypertension and normal cholesterol levels," Journal of Hypertension, vol. 29, no. 9, pp. 1757-1764, 2011.

[122] M. Vasa, S. Fichtlscherer, K. Adler et al., "Increase in circulating endothelial progenitor cells by statin therapy in patients with stable coronary artery disease," Circulation, vol. 103, no. 24, pp. 2885-2890, 2001.

[123] C. Szabõ, "Hydrogen sulphide and its therapeutic potential," Nature Reviews Drug Discovery, vol. 6, no. 11, pp. 917-935, 2007.

[124] D.-D. C. Fang Liu, X. Sun, H.-H. Xie, H. Yuan, W. Jia, and A. F. Chen, "Hydrogen sulfide improves wound healing via restoration of endothelial progenitor cell functions and activation of angiopoietin-1 in type 2 diabetes," Diabetes, vol. 63, no. 5, pp. 1763-1778, 2014.

[125] Z. Gu, M. Kaul, B. Yan et al., "S-nitrosylation of matrix metalloproteinases: signaling pathway to neuronal cell death," Science, vol. 297, no. 5584, pp. 1186-1190, 2002.

[126] K. J. Hurt, B. Musicki, M. A. Palese et al., "Akt-dependent phosphorylation of endothelial nitric-oxide synthase mediates penile erection," Proceedings of the National Academy of Sciences of the United States of America, vol. 99, no. 6, pp. 4061-4066, 2002.

[127] K.-E. Andersson, "Pharmacology of penile erection," Pharmacological Reviews, vol. 53, no. 3, pp. 417-450, 2001.

[128] K. L. March and B. H. Johnstone, "Cellular approaches to tissue repair in cardiovascular disease: the more we know, the more there is to learn," American Journal of Physiology-Heart and Circulatory Physiology, vol. 287, no. 2, pp. H458-H463, 2004.

[129] B. Glotzbecker, C. Duncan, E. Alyea III, B. Campbell, and R. Soiffer, "Important drug interactions in hematopoietic stem cell transplantation: what every physician should know," Biology of Blood and Marrow Transplantation, vol. 18, no. 7, pp. 989-1006, 2012. 
[130] J. L. Herrmann, Y. Wang, A. M. Abarbanell, B. R. Weil, J. Tan, and D. R. Meldrum, "Preconditioning mesenchymal stem cells with transforming growth factor-alpha improves mesenchymal stem cell-mediated cardioprotection," Shock, vol. 33, no. 1, pp. 24-30, 2010.

[131] Q. Gu, C. Chen, Z. Zhang et al., "Ginkgo biloba extract promotes osteogenic differentiation of human bone marrow mesenchymal stem cells in a pathway involving Wnt/ $\beta$-catenin signaling," Pharmacological Research, vol. 97, pp. 70-78, 2015.

[132] H. K. Haider and M. Ashraf, "Preconditioning and stem cell survival," Journal of Cardiovascular Translational Research, vol. 3, no. 2, pp. 89-102, 2010.

[133] A. V. Skriptsova, "Fucoidans of brown algae: biosynthesis, localization, and physiological role in Thallus," Russian Journal of Marine Biology, vol. 41, no. 3, pp. 145-156, 2015.

[134] S.-B. Park, K.-R. Chun, J.-K. Kim, K. Suk, Y.-M. Jung, and W.H. Lee, "The differential effect of high and low molecular weight fucoidans on the severity of collagen-induced arthritis in mice," Phytotherapy Research, vol. 24, no. 9, pp. 1384-1391, 2010.

[135] H.-J. Boo, J.-Y. Hong, S.-C. Kim et al., "The anticancer effect of fucoidan in PC-3 prostate cancer cells," Marine Drugs, vol. 11, no. 8, pp. 2982-2999, 2013.

[136] M.-J. Kim, J. Jeon, and J.-S. Lee, "Fucoidan prevents high-fat diet-induced obesity in animals by suppression of fat accumulation," Phytotherapy Research, vol. 28, no. 1, pp. 137-143, 2014.

[137] K. Bojakowski, P. Abramczyk, M. Bojakowska, A. Zwolińska, J. Przybylski, and Z. Gaciong, "Fucoidan improves the renal blood flow in the early stage of renal ischemia/reperfusion injury in the rat," Journal of Physiology and Pharmacology, vol. 52, no. 1, pp. 137-143, 2001.

[138] S.-W. Hong, H.-S. Lee, K. H. Jung, H. Lee, and S.-S. Hong, "Protective effect of fucoidan against acetaminophen-induced liver injury," Archives of Pharmacal Research, vol. 35, no. 6, pp. 1099-1105, 2012.

[139] J. H. Lee, S. H. Lee, S. H. Choi, T. Asahara, and S.-M. Kwon, “The sulfated polysaccharide fucoidan rescues senescence of endothelial colony-forming cells for ischemic repair," Stem Cells, vol. 33, no. 6, pp. 1939-1951, 2015.

[140] W.-Y. Lee, H.-Y. Chen, K.-C. Chen, and C. Y.-C. Chen, “Treatment of rheumatoid arthritis with traditional Chinese medicine," BioMed Research International, vol. 2014, Article ID 528018, 11 pages, 2014.

[141] N. Ji, J. Li, Z. Wei et al., "Effect of celastrol on growth inhibition of prostate cancer cells through the regulation of hERG channel in vitro," BioMed Research International, vol. 2015, Article ID 308475, 7 pages, 2015.

[142] A. Trott, J. D. West, L. Klaić et al., "Activation of heat shock and antioxidant responses by the natural product celastrol: transcriptional signatures of a thiol-targeted molecule," Molecular Biology of the Cell, vol. 19, no. 3, pp. 1104-1112, 2008.

[143] B. Astry, S. H. Venkatesha, A. Laurence et al., "Celastrol, a Chinese herbal compound, controls autoimmune inflammation by altering the balance of pathogenic and regulatory $\mathrm{T}$ cells in the target organ," Clinical Immunology, vol. 157, no. 2, pp. 228238, 2015

[144] C. Lu, X. Yu, K. Zuo et al., “Tripterine treatment improves endothelial progenitor cell function via integrin-linked kinase," Cellular Physiology and Biochemistry, vol. 37, no. 3, pp. 1089-1103, 2015.

[145] W. Douglas and J. M. I. Losordo, "Estrogen and angiogenesis," Arteriosclerosis, Thrombosis, and Vascular Biology, vol. 21, pp. 612, 2001.
[146] L. M. Walter, P. A. W. Rogers, and J. E. Girling, "The role of progesterone in endometrial angiogenesis in pregnant and ovariectomised mice," Reproduction, vol. 129, no. 6, pp. 765-777, 2005.

[147] J. Fishman, J. B. Brown, L. Hellman, B. Zumoff, and T. F. Gallagher, "Estrogen metabolism in normal and pregnant women," The Journal of biological chemistry, vol. 237, pp. 1489-1494, 1962.

[148] Y. Matsubara and K. Matsubara, "Estrogen and progesterone play pivotal roles in endothelial progenitor cell proliferation," Reproductive Biology and Endocrinology, vol. 10, article no. 2, 2012.

[149] X. Zhao, L. Huang, Y. Yin, Y. Fang, J. Zhao, and J. Chen, "Estrogen induces endothelial progenitor cells proliferation and migration by estrogen receptors and PI3K-dependent pathways," Microvascular Research, vol. 75, no. 1, pp. 45-52, 2008.

[150] T. Imanishi, T. Hano, and I. Nishio, "Estrogen reduces endothelial progenitor cell senescence through augmentation of telomerase activity," Journal of Hypertension, vol. 23, no. 9, pp. 16991706, 2005.

[151] X.-B. Wang, J. Huang, J.-G. Zou et al., "Effects of resveratrol on number and activity of endothelial progenitor cells from human peripheral blood," Clinical and Experimental Pharmacology and Physiology, vol. 34, no. 11, pp. 1109-1115, 2007.

[152] P. Jeandet, "Phytoalexins: current progress and future prospects," Molecules, vol. 20, no. 2, pp. 2770-2774, 2015.

[153] B. D. Gehm, J. M. McAndrews, P.-Y. Chien, and J. L. Jameson, "Resveratrol, a polyphenolic compound found in grapes and wine, is an agonist for the estrogen receptor," Proceedings of the National Academy of Sciences of the United States of America, vol. 94, no. 25, pp. 14138-14143, 1997.

[154] T. Wallerath, G. Deckert, T. Ternes et al., "Resveratrol, a polyphenolic phytoalexin present in red wine, enhances expression and activity of endothelial nitric oxide synthase," Circulation, vol. 106, no. 13, pp. 1652-1658, 2002.

[155] S. H. Lee, J. H. Lee, T. Asahara et al., "Genistein promotes Endothelial Colony-Forming Cell (ECFC) bioactivities and cardiac regeneration in myocardial infarction," PLOS ONE, vol. 9, no. 5, Article ID e96155, 2014.

[156] M. Donoghue, F. Hsieh, E. Baronas et al., "A novel angiotensinconverting enzyme-related carboxypeptidase (ACE2) converts angiotensin I to angiotensin 1-9," Circulation research, vol. 87, no. 5, pp. E1-E9, 2000.

[157] J. A. Stewart, E. Lazartigues, and P. A. Lucchesi, "The angiotensin converting enzyme 2/Ang-(1-7) axis in the heart: a role for mas communication?" Circulation Research, vol. 103, no. 11, pp. 1197-1199, 2008.

[158] A. Soro-Paavonen, D. Gordin, C. Forsblom et al., "Circulating ACE2 activity is increased in patients with type 1 diabetes and vascular complications," Journal of Hypertension, vol. 30, no. 2, pp. 375-383, 2012.

[159] J. Chen, X. Xiao, S. Chen et al., "Angiotensin-converting enzyme 2 priming enhances the function of endothelial progenitor cells and their therapeutic efficacy," Hypertension, vol. 61, no. 3, pp. 681-689, 2013.

[160] F. Fleissner and T. Thum, "The IGF-1 receptor as a therapeutic target to improve endothelial progenitor cell function," Molecular Medicine, vol. 14, no. 5-6, pp. 235-237, 2008.

[161] S. Sen, J. Merchan, J. Dean et al., "Autologous transplantation of endothelial progenitor cells genetically modified by adenoassociated viral vector delivering insulin-like growth factor-1 gene after myocardial infarction," Human Gene Therapy, vol. 21, no. 10, pp. 1327-1334, 2010. 
[162] M. Widmaier, E. Rognoni, K. Radovanac, S. B. Azimifar, and R. Fässler, "Integrin-linked kinase at a glance," Journal of Cell Science, vol. 125, no. 8, pp. 1839-1843, 2012.

[163] F. Wang, Y. Wang, L. Zhang, and L. Zou, "Gene modification with integrin-linked kinase improves function of endothelial progenitor cells in pre-eclampsia in vitro," Journal of Cellular Biochemistry, vol. 112, no. 11, pp. 3103-3111, 2011.

[164] J. H. Lee, S. H. Lee, S. Y. Yoo, T. Asahara, and S.-M. Kwon, "CD34 hybrid cells promote endothelial colony-forming cell bioactivity and therapeutic potential for ischemic diseases," Arteriosclerosis, Thrombosis, and Vascular Biology, vol. 33, no. 7, pp. 1622-1634, 2013.

[165] D. J. Sieg, C. R. Hauck, and D. D. Schlaepfer, "Required role of focal adhesion kinase (FAK) for integrin-stimulated cell migration," Journal of Cell Science, vol. 112, no. 16, pp. 2677-2691, 1999.

[166] H. Zigdon-Giladi, T. Bick, D. Lewinson, and E. E. Machtei, "Co-Transplantation of endothelial progenitor cells and mesenchymal stem cells promote neovascularization and bone regeneration," Clinical Implant Dentistry and Related Research, vol. 17, no. 2, pp. 353-359, 2013.

[167] J. Yang, Y. Kang, C. Browne, T. Jiang, and Y. Yang, "Graded porous $\beta$-tricalcium phosphate scaffolds enhance bone regeneration in mandible augmentation," Journal of Craniofacial Surgery, vol. 26, no. 2, pp. e148-e153, 2015.

[168] M. L. Graham, J. L. Janecek, J. A. Kittredge, B. J. Hering, and H.-J. Schuurman, "The streptozotocin-induced diabetic nude mouse model: differences between animals from different sources," Comparative Medicine, vol. 61, no. 4, pp. 356-360, 2011.

[169] L. C. Perlmuter, B. P. Flanagan, P. H. Shah, and S. P. Singh, "Glycemic control and hypoglycemia," Diabetes Care, vol. 31, no. 10, pp. 2072-2076, 2008.

[170] H. Ilgun, J. W. Kim, and L. Luo, "Adult stem cells and diabetes therapy," Journal of Stem Cell Research and Transplantation, vol. 2, no. 2, article 1020, 2015.

[171] M. Gnecchi, Z. Zhang, A. Ni, and V. J. Dzau, "Paracrine mechanisms in adult stem cell signaling and therapy," Circulation Research, vol. 103, no. 11, pp. 1204-1219, 2008.

[172] E. Lázár-Molnár, H. Hegyesi, S. Tóth, and A. Falus, "Autocrine and paracrine regulation by cytokines and growth factors in melanoma," Cytokine, vol. 12, no. 6, pp. 547-554, 2000.

[173] B. Doyle, P. Sorajja, B. Hynes et al., "Progenitor cell therapy in a porcine acute myocardial infarction model induces cardiac hypertrophy, mediated by paracrine secretion of cardiotrophic factors including TGF $\beta 1$," Stem Cells and Development, vol. 17, no. 5, pp. 941-951, 2008.

[174] C. Urbich, A. Aicher, C. Heeschen et al., "Soluble factors released by endothelial progenitor cells promote migration of endothelial cells and cardiac resident progenitor cells," Journal of Molecular and Cellular Cardiology, vol. 39, no. 5, pp. 733-742, 2005.

[175] S. Di Santo, A. Fuchs, R. Periasamy, S. Seiler, and H. R. Widmer, "The cytoprotective effects of human endothelial progenitor cell-conditioned medium against an ischemic insult are not dependent on VEGF and IL-8," Cell Transplantation, vol. 25, no. 4, pp. 735-747, 2016.

[176] V. Muralidharan-Chari, J. W. Clancy, A. Sedgwick, and C. D'Souza-Schorey, "Microvesicles: mediators of extracellular communication during cancer progression," Journal of Cell Science, vol. 123, no. 10, pp. 1603-1611, 2010.

[177] S. Gu, W. Zhang, J. Chen et al., "EPC-derived microvesicles protect cardiomyocytes from Ang II-induced hypertrophy and apoptosis," PLoS ONE, vol. 9, no. 1, Article ID e85396, 2014.
[178] M. C. Deregibus, V. Cantaluppi, R. Calogero et al., "Endothelial progenitor cell-derived microvesicles activate an angiogenic program in endothelial cells by a horizontal transfer of mRNA," Blood, vol. 110, no. 7, pp. 2440-2448, 2007.

[179] B. R. Everaert, E. M. Van Craenenbroeck, V. Y. Hoymans et al., "Current perspective of pathophysiological and interventional effects on endothelial progenitor cell biology: focus on Pi3K/ AKT/eNOS pathway," International Journal of Cardiology, vol. 144, no. 3, pp. 350-366, 2010.

[180] D. Schmidt, C. Breymann, A. Weber et al., "Umbilical cord blood derived endothelial progenitor cells for tissue engineering of vascular grafts," Annals of Thoracic Surgery, vol. 78, no. 6, pp. 2094-2098, 2004.

[181] T. Shirota, H. Yasui, H. Shimokawa, and T. Matsuda, "Fabrication of endothelial progenitor cell (EPC)-seeded intravascular stent devices and in vitro endothelialization on hybrid vascular tissue," Biomaterials, vol. 24, no. 13, pp. 2295-2302, 2003.

[182] J. L. Ifkovits and J. A. Burdick, "Review: photopolymerizable and degradable biomaterials for tissue engineering applications," Tissue Engineering, vol. 13, no. 10, pp. 2369-2385, 2007.

[183] T. Masuda, M. Furue, and T. Matsuda, "Photocured, styrenated gelatin-based microspheres for de novo adipogenesis through corelease of basic fibroblast growth factor, insulin, and insulinlike growth factor I," Tissue Engineering, vol. 10, no. 3-4, pp. 523535, 2004.

[184] J. A. Leopold, "Prohealing endothelial progenitor cell capture stents do the cells captured explain the clinical outcomes?" Circulation: Cardiovascular Interventions, vol. 6, no. 5, pp. 494-495, 2013.

[185] V. Farooq, B. D. Gogas, and P. W. Serruys, "Restenosis: delineating the numerous causes of drug-eluting stent restenosis," Circulation: Cardiovascular Interventions, vol. 4, no. 2, pp. 195205, 2011.

[186] E. B. Peters, N. Christoforou, K. W. Leong, G. A. Truskey, and J. L. West, "Poly(Ethylene Glycol) hydrogel scaffolds containing cell-adhesive and protease-sensitive peptides support microvessel formation by endothelial progenitor cells," Cellular and Molecular Bioengineering, vol. 9, no. 1, pp. 38-54, 2016.

[187] J. Zhu, "Bioactive modification of poly(ethylene glycol) hydrogels for tissue engineering," Biomaterials, vol. 31, no. 17, pp. 4639-4656, 2010.

[188] J.-Z. Du, T.-M. Sun, S.-Q. Weng, X.-S. Chen, and J. Wang, "Synthesis and characterization of photo-cross-linked hydrogels based on biodegradable polyphosphoesters and poly(ethylene glycol) copolymers," Biomacromolecules, vol. 8, no. 11, pp. 33753381, 2007. 

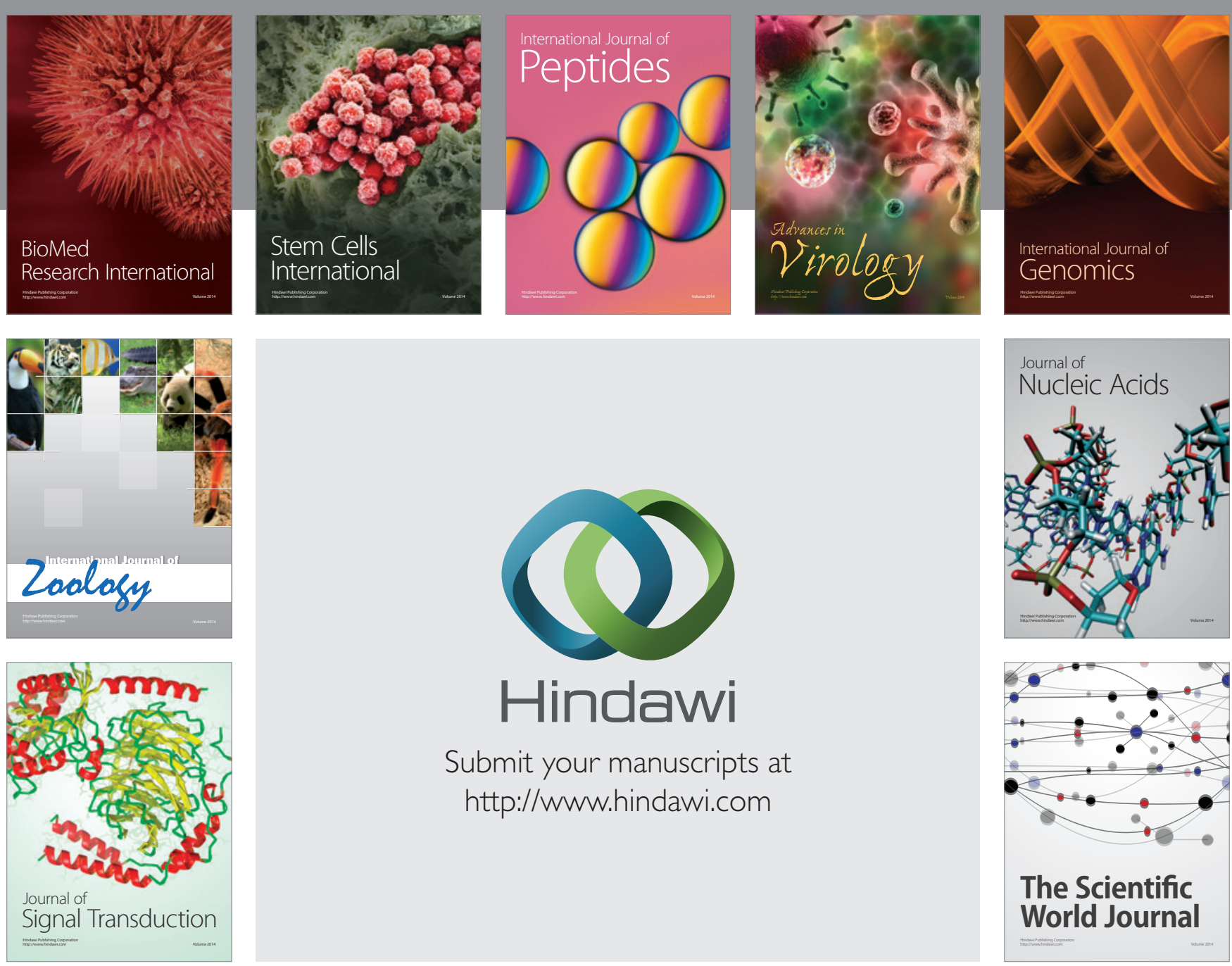

Submit your manuscripts at

http://www.hindawi.com
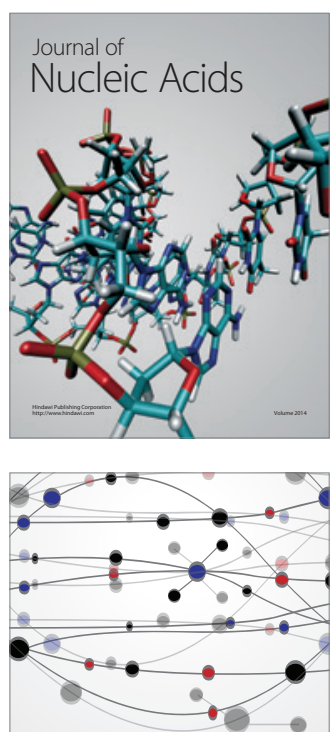

The Scientific World Journal
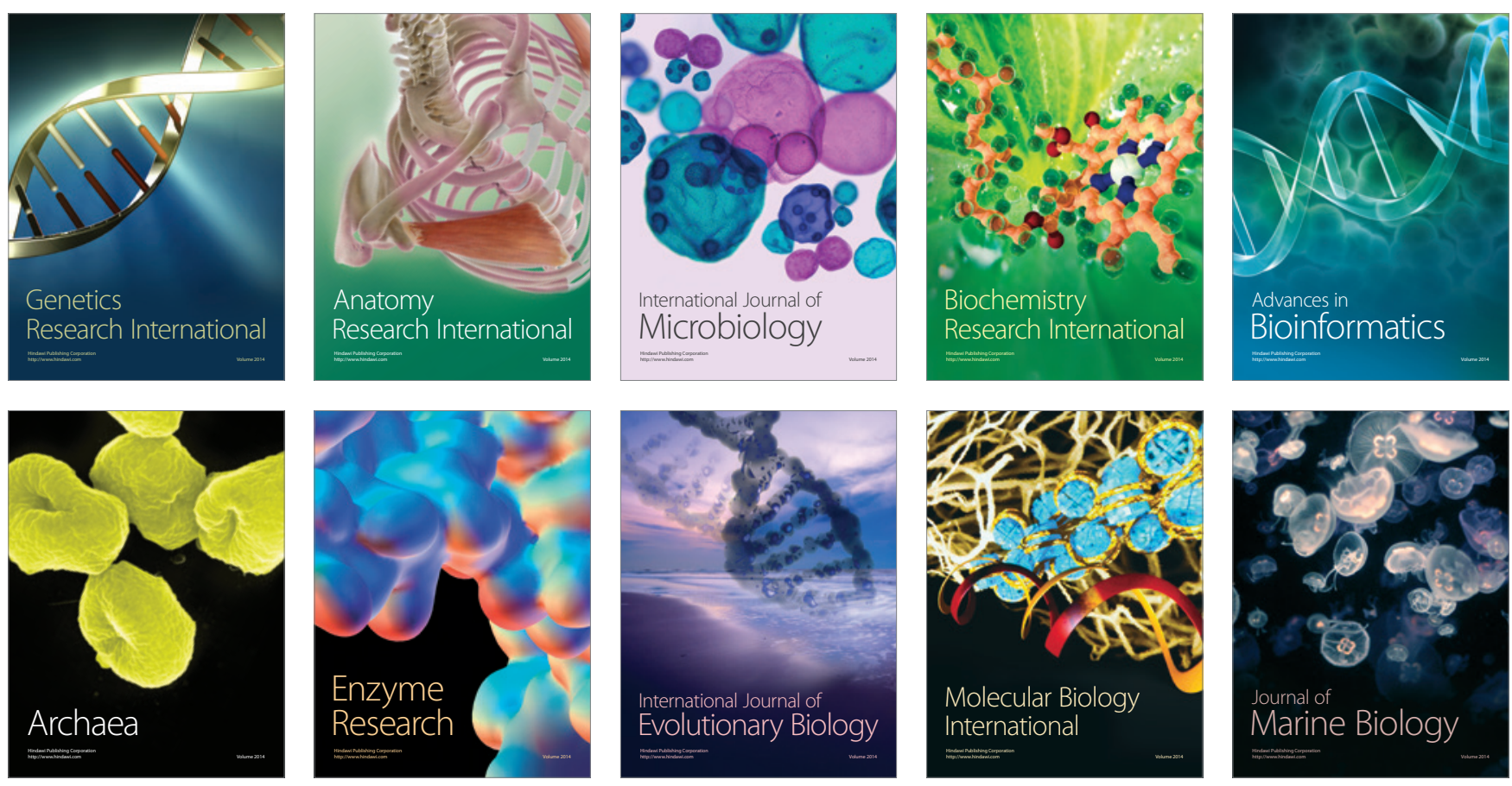